\title{
The Challenges Facing The Accounting Profession Under The Coronavirus Pandemic (COVID-19)
}

Journal of

\section{TANMIYAT AL- RAFIDAIN}

\section{(TANRA)}

A scientific, quarterly, international, open access, and peer-reviewed journal

Vol. 39, No. 128

Dec., 2020

(C) University of Mosul | College of Administration and Economics, Mosul, Iraq.

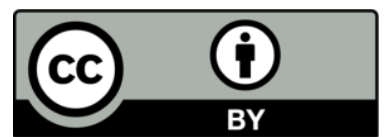

TANRA retain the copyright of published articles, which is released under a "Creative Commons Attribution License for CC-BY-4.0" enabling the unrestricted use, distribution, and reproduction of an article in any medium, provided that the original work is properly cited.

Citation: Ardiny ; Taha; A. H. (2020)." The Challenges Facing The Accounting Profession Under The Coronavirus Pandemic (COVID-19) TANMIYAT ALRAFIDAIN, 39 (128), 196-219, https://doi.org/10.33899/tanra.20 20.167375

P-ISSN: 1609-591X e-ISSN: 2664-276X tanmiyat.mosuljournals.com

\section{Taha A. H. Ardiny}

Department of Accounting, College of Administration and Economics, University of Mosul

Corresponding author: Taha A. H. Ardiny, Taha ahmed@uomosul.edu.iq DOI: 10.33899/tanra.2020.167375

Article History: Received: 4/9/2020; Revised: 19/9/2020; Accepted: 27/9/2020; Published: $1 / 12$ /2020.

\section{Abstract}

The research highlights the challenges facing accountants and professional regulators when dealing with the impact of the virus (COVID-19) pandemic on the elements of the financial statements of economic units, and on the results of their operations and their financial position in the year ending 12/31/2019 and beyond, as well as the extent of the need to amend international financial reporting standards as a result of the crisis of the COVID-19 pandemic, as it happens every time when Global financial crisis it occurs.

The research reviewed the published data and reports on international and local professional organizations interested in accounting, such as IFRS, IOSCO, IPSASB, GAAP US, ESMA, AASB - AUASB, as well as the Iraqi Auditing Profession Council, and stating the position of these organizations on the COVID19 pandemic.

The researcher reached a set of results, the most important of which is that there are a set of challenges that are most influencing the financial statements for the period ending on 12/31/2020, which require accountants and professional organizers with accounting treatments and special disclosures as a result of the uncertainty caused by the virus (COVID-19) pandemic, including the book value For non-financial and intangible assets, including goodwill, as well as cash flow difficulties, credit losses, and disclosures related to the imposition of continuity and the accompanying disclosures. Despite these challenges, there is a consensus on the part of international accounting professional bodies and organizations confirming the ability of standards to address these effects and that there is no need to amend, change, delete or add to the requirements of the standards, especially International Financial Reporting Standard No. (9) "Financial Instruments. ".

Keywords:

COVID-19, accounting professional organizations, financial statements, International Financial Reporting Standard No. (9) "Financial Instruments", International Accounting Standard No. (10) "Subsequent events". 


\section{ورقة بحثية التحديات التي تواجه مهنة المحاسبة في ظل جائحة فيروس كورونا (COVID-19)}

طه أحمد حسن أرديني جامعة الموصل، كلية الإدارة والاقتصاد، قسم المحاسبة

المؤلف المراسل: طه أحمد حسن أرديني، Taha ahmed@uomosul.edu.iq
DOI: $10.33899 /$ tanra.2020.167375

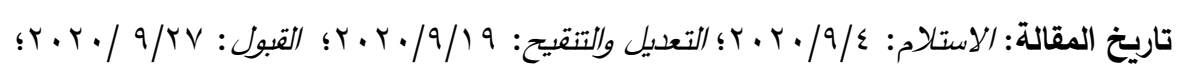

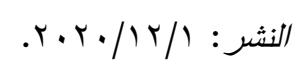

المستخلص

يسلط البحث الضوء على التحديات التي تواجه المحاسبين ومنظمي المهنة عند معالجة تأثير جائحة فيروس

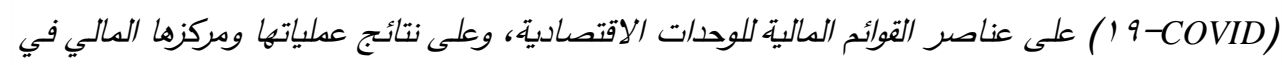

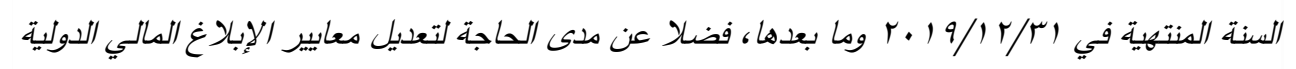
نتيجة أزمة جائحة فيروس COVID-9 ا كما يحصل في كل مرة عندما تحصل أزمة مالية عالمية. قام الباحث بالاطلاع على ما تم نشره من بيانات وتقارير عن المنظمات المهنية الدولية والمحلية المهتمة بالمحاسبة مثل AASB-AUASB، ESMA،GAAP US،IPSASB ، IOSCO،IFRS ، فضلاً عن مجلس

مهنة مراقبة وتدقيق الحسابات العراقي، وبيان موقف هذه المنظمات من جائحة فيروس وقد توصل الباحث إلى مجدوعة من النتائج أههها ، إن هناك مجدوعة من التحديات والتحي تعد الأكثر تأثيرًا

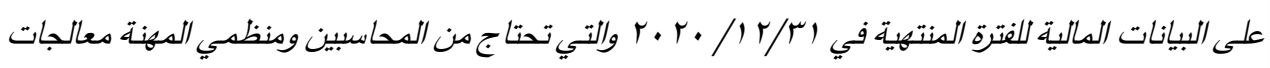
محاسبية وافصاحات خاصة نتيجة لحالة عدم التأكد الناجدة عن جائحة فيروس(COVID-19) ومنها القيمة الدفترية للأصول غير المالي والأصول غير الملموسة بما فيها الثهرة، فضلا عن صعوبات التدفق النقدي والخسائر الائتمانية والإفصاحات المتعلقة بنرض الاستمراية والافصاحات المصاحبة لها. وبالرغم من هذه التحديات ال ان هناك اجماع من قبل الهيئات والمنظمات المهنية الدولية المحاسبية يؤكد على قدرة المعايير في معالجة هذه التأثيرات، وأنه لا حاجة إلى تعديل أو تغيير أو حذف أو إضافة إلى متطلبات المعايير،

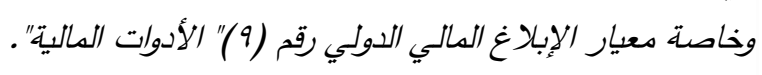

الكلمات المفتاحية:

COVID المالي الدولي رقم (9)"الأدوات المالية"، معيار المحاسبة الدولي رقم ( • 1) "الأحداث النلاحقة

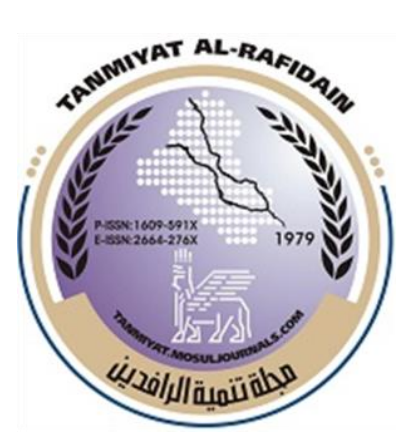

\section{تنمية الرافدين}

دولية، (TANRA) دولية، مفتوحة الوصول، محكمة.

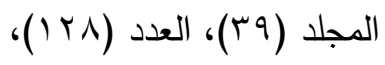

$$
\begin{aligned}
& \text { كانون الاول .r.r. }
\end{aligned}
$$

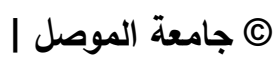
كلية الإدارة والاقتصاد، الموصل، العراق.

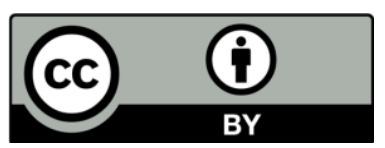

تحتفظ (TANRA) بحقوق الطبع والنشر للمقالات

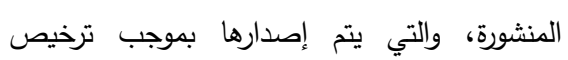
」 (Creative Commons Attribution) (CC-BY-4.0)

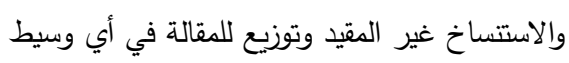
نقل، بشرط اقتباس العمل الأصلي بثكل صحيح. الاقتباس: طه أحمد حسن أرديني ( • • • ) ).

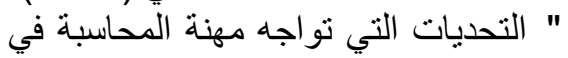
ظل جائحة فيروس كورونا (

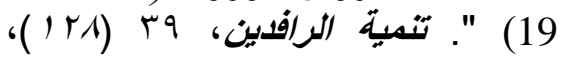
6) $9-197$ https://doi.org/10.33899/tanra.20 20.167375

P-ISSN: 1609-591X e-ISSN: 2664-276X tanmiyat.mosuljournals.com 
مع زيادة تفشي جائحة فيروس كورونا (COVID-19) من حيث الحجم والمدة الزمنية التي لم تنتهِ حتى إعداد هذا البحث، والذي أنعكس بشكل مباشر على الصحة العامة، أدى إلى فرض قيود على حركة

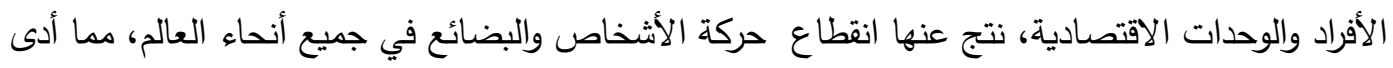
إلى تأثير سلبي جوهري على المركز المالي للوحدات الاقتصادية وعملياتها وتدفقاتها النقدية. فقد شملت الآثار المحتملة على الوحدات الاقتصادية، على سبيل المثال لا الحصر، تعطل عملاء الوحدات الاقتصادية

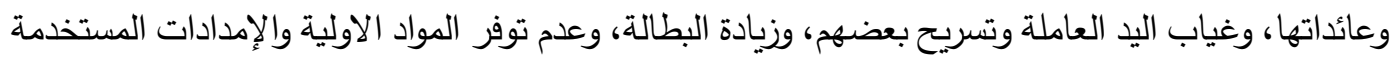

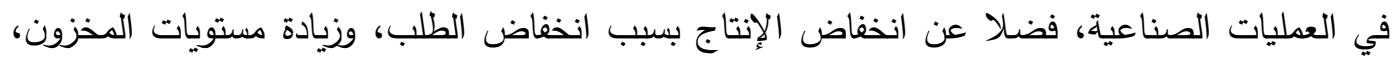

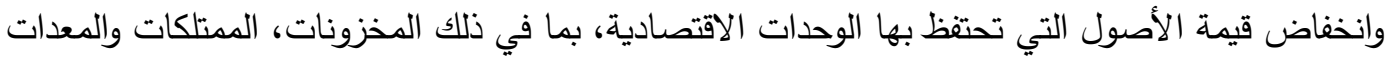

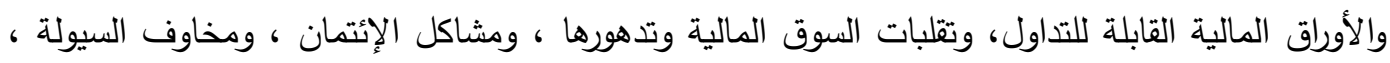

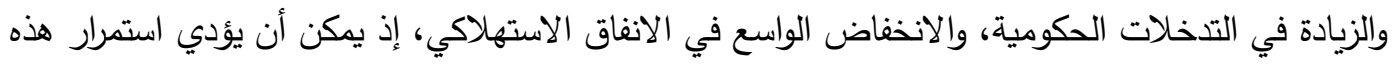

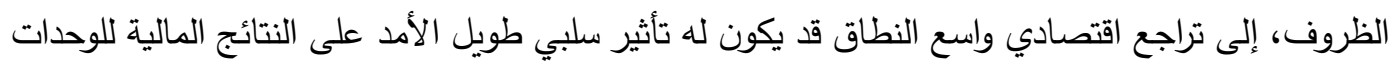
الاقتصادية وعلى مبدأ الاستمرارية عند إعداد القوائم المالية.

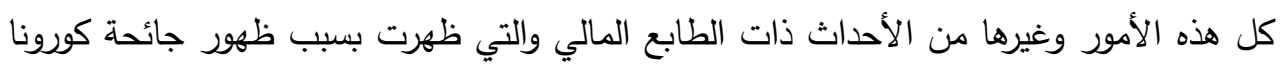
(COVID-19)

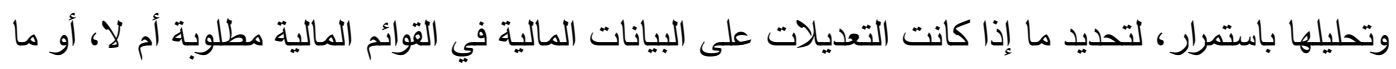
إذا كانت الإفصاحات الإضافية ضرورية أم لا. كل هذه الأمور وغيرها، تعد بمثابة تحديات تواجه المحاسبين

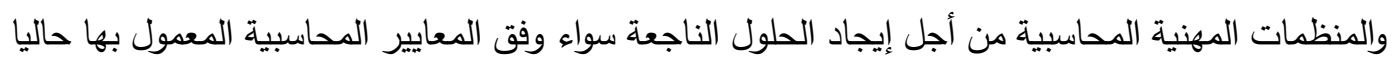
أو بإيجاد معالجات مستحدثة لم تكن قد تتبهت لها المنظمات المهنية من قبل. ثانياً: هدف البحث

يهدف البحث إلى تسليط الضوء على التحديات التي تواجه المحاسبين ومنظمي المهنة عند معالجة آثار تفثي جائحة فيروس ( COVID-19على الوحدات الاقتصادية، وعلى النتائج عملياتها ومركزها المالي،

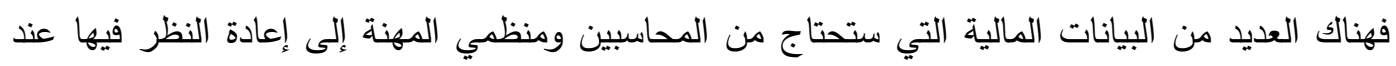

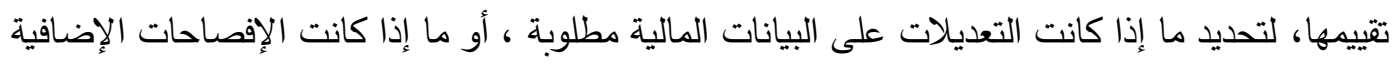

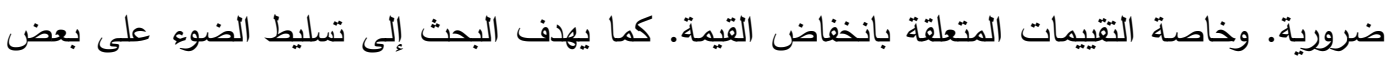
البيانات المالية الرئيسة التي قد تتأثر بـ (COVID-19). وردة فعل مهنة المحاسبة من خلال منظماتها المهنية

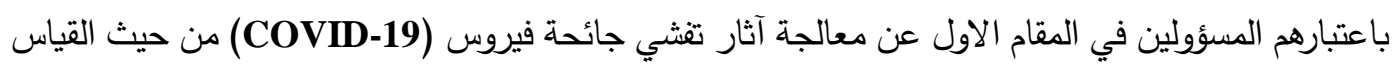
والافصاح في القوائم والتقارير المالية. 
أرديني

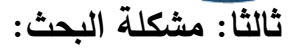

يمكن تحديد مشكلة البحث من خلال طرح التساؤلات الآتية:-

1. ما موقف الهيئات والمنظمات المهنية الدولية والمحلية المنظمة لمهنة المحاسبة من جائحة فيروس

? COVID-19

r. هل هناك حاجة لتعديل المعايير الدولية للإبلاغ المالي نتيجة لأزمة جائحة فيروس (COVID-19) كما

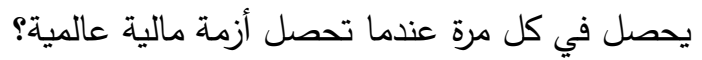

r. هل ينبغي اعتبار جائحة فيروس (COVID-19) حدث يتم على أساسه تعديل القوائم المالية للسنة

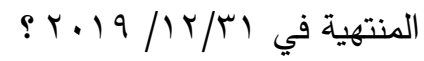

ع. . ما التحديات التي تواجه المحاسبين ومنظمي المهنة لمعالجة تأثير جائحة فيروس (COVID-19) على

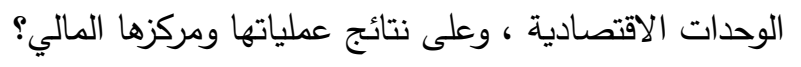

رابعاً: أهمية البحث

تأتي أهية البحث من تسليطه الضوء على التحديات التي تواجه مهنة المحاسبة في ظل تفشي جائحة

فيروس (COVID-19)، فضلا عن تأثيراته على القوائم المالية، والمعالجات المحاسبية اللازمة لهذه التأثيرات

$$
\text { على عناصر القوائم المالية. }
$$

خامساً: فرضية البحث

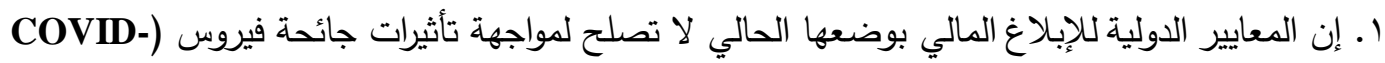

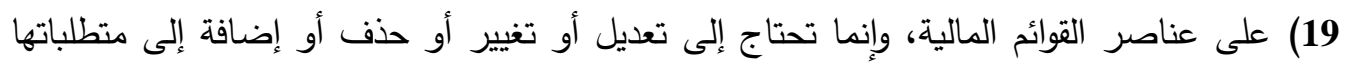

$$
\text { فضلا عن الايضاحات الملحقة بها. }
$$

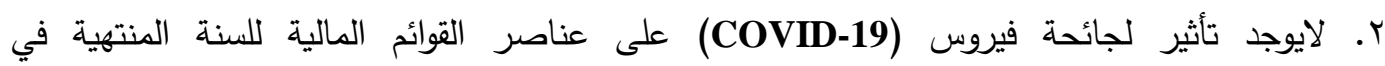

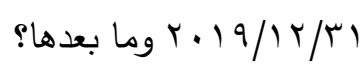

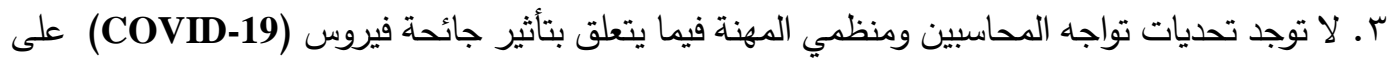

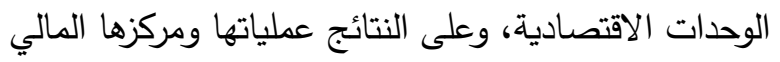

$$
\begin{aligned}
& \text { خطة البحث } \\
& \text { تم تقسيم البحث على أربعة محاور تتمثل بالآتي: } \\
& \text { المحور الأول: تأثير جائحة فيروس (COVID-19) على الوحدات الاقتصادية }
\end{aligned}
$$

المحور الثاني: موقف المنظمات المهنية المحاسبية من معالجة تأثيرات جائحة فيروس (COVID-19)

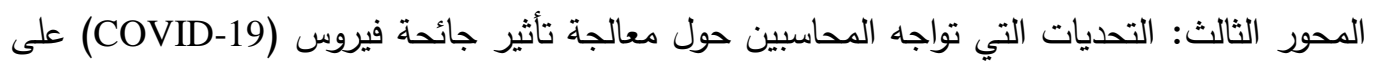
القوائم المالية، وقد تم تقسيم هذا المحور على الآتي: تولهات 
أولاً: التحديات التي تواجه المحاسبين حول معالجة تأثير جائحة فيروس (COVID-19) على القوائم المالية

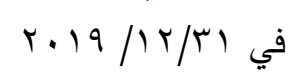

ثانياً: التحديات التي تواجه المحاسبين حول معالجة تأثير جائحة فيروس (COVID-19) على القوائم المالية

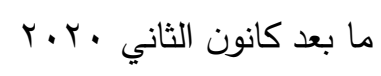

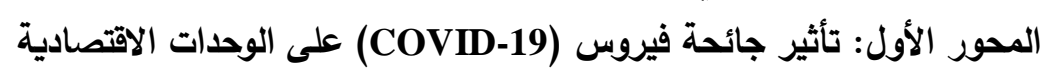

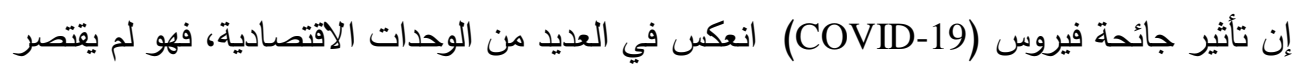

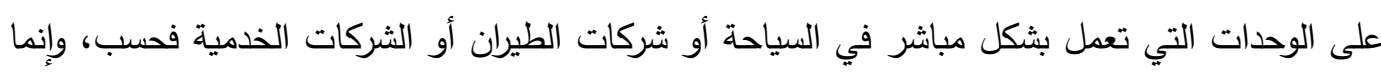

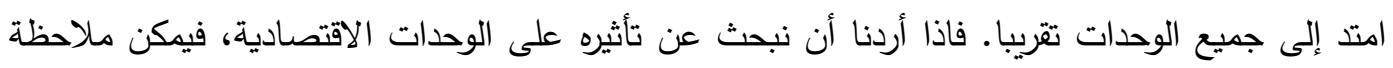

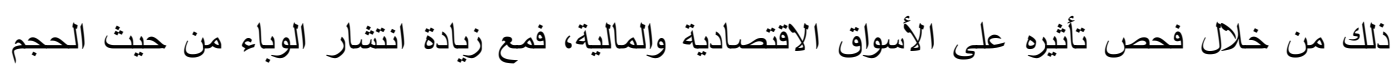

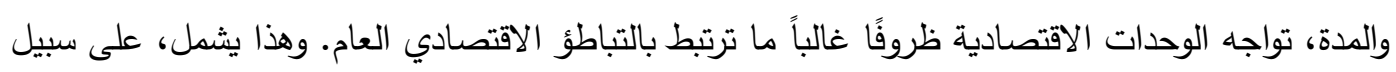

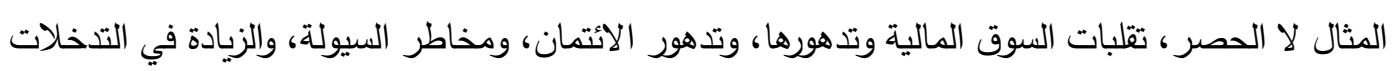

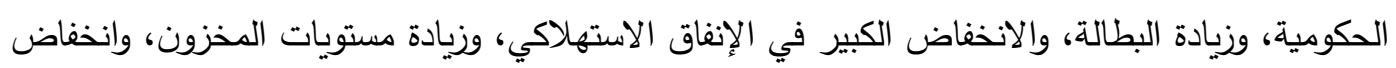

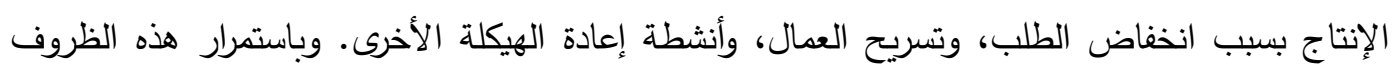

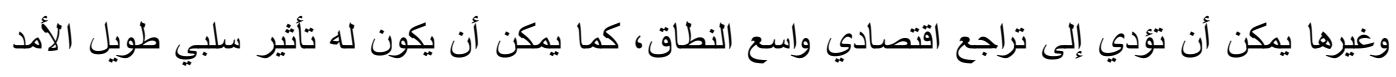

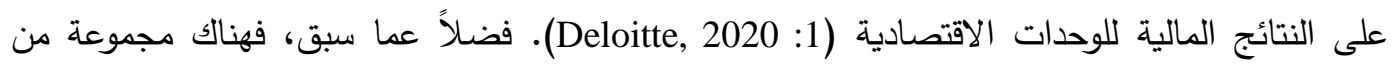
التأثيرات الأخرى التي حصلت نتيجة لانتشار جائحة فيروس (COVID-19) والتي يمكن أن يكون لها تأثير

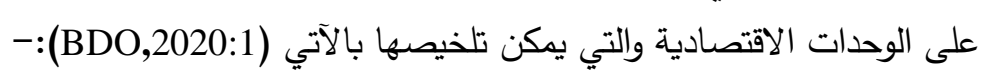

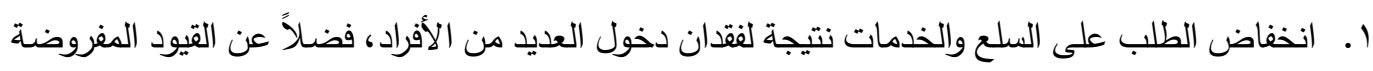

$$
\text { على قدرة المستهلكين على التنقل بحرية. }
$$

r r. تعطيل سلاسل التوريد العالمية بسبب القيود المفروضة على حركة الاشخاص والبضائع. r. ب. نقص في الاستثمارات الرأسمالية وحركة البناء، مما يقلل من الطلب على العلى العديد من السلع والخدمات.

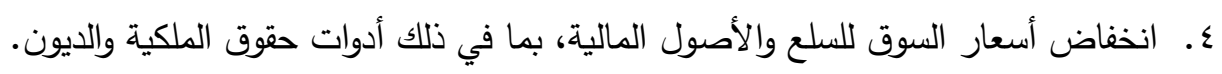

المحور الثاني: موقف المنظمات المهنية المحاسبية من معالجة تأثيرات جائحة فيروس (COVID-19)

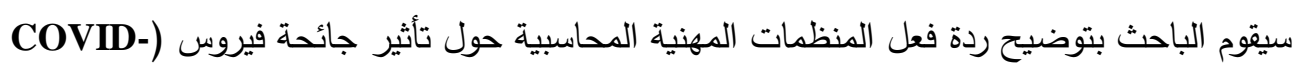
19) وذلك من خلال مناقثة المقالات والتقارير والبيانات الصادرة عنها، وذلك من خلال الآتي: 
ا ـ موقف مجلس المعايير الدولية للإبلاغ المالي (IFRS) في ضوء تظورات جائحة فيروس (-COVID)

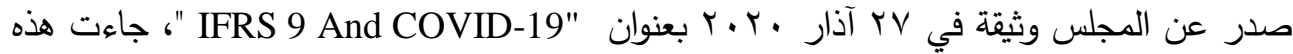
الوثيقة لتجيب على عدد من الأسئلة المتعلقة بتطبيق المعيار الدولي للتقارير المالية رقم (9) "الأدوات المالية" لعنية

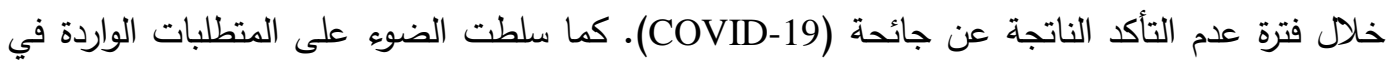
المعيار الدولي للتقارير المالية رقم (9) ذات الصلة بالوحدات التي تتظر في كيفية تأثير الوباء على حساباتها

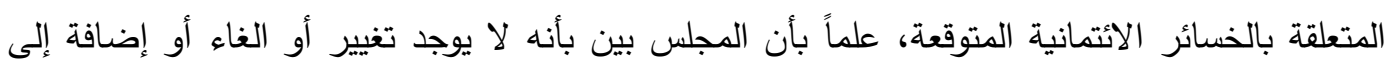

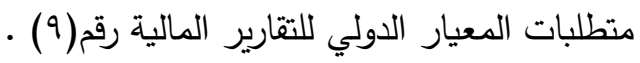

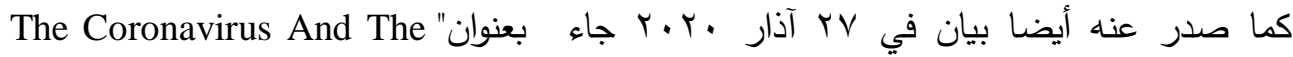
Foundation's Work" ، والذي أقرت فيه بأن هذا الوقت صعب بالنسبة لأصحاب المصلحة، كما يوفر باء بان البيان معلومات عن العمل الذي يقوم به المجلس لاعم أصحاب المصلحة.

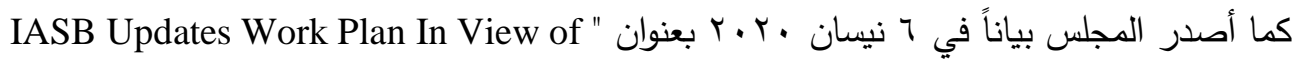
COVID-19 Developments

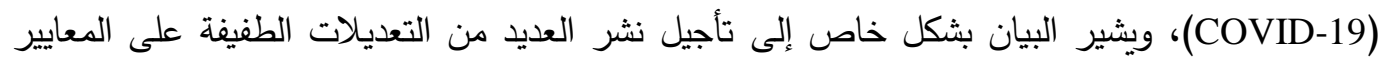

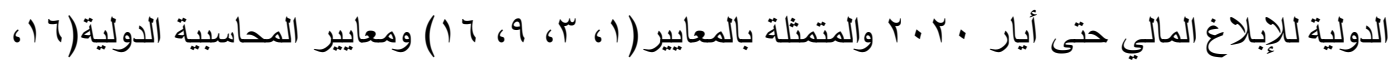

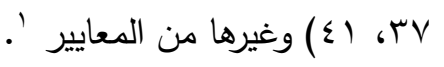

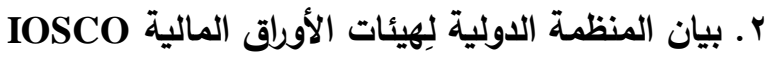

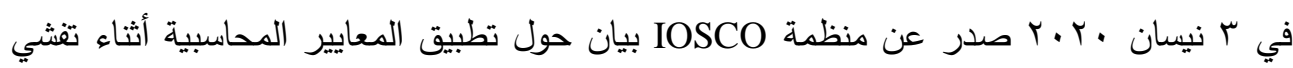
جائحة فيروس (COVID-19) جاء بعنوان "IOSCO Statement On The Application Of Accounting Standards During The COVID-19 Outbreak التي وضعها مجلس معايير المحاسبة الدولية، والتي تتاولت تطبيق المحاسبة عن الخسائر الائتمانية المتوقعة وفقًا للمعيار الدولي للتقارير المالية رقم (9) "الأدوات المالية" ،خلال فترة عدم التأكد الناشئة عن تفشي جائحة فيروس (COVID-19). كما بين البيان أيضاً، بأن متطلبات الإفصاح المستندة إلى مبادئ الأدوات المالية

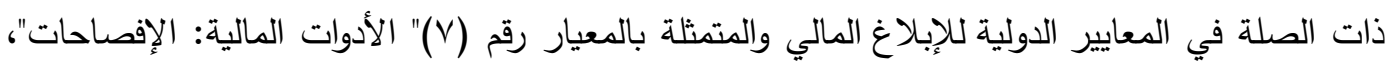
ومعيار المحاسبة الدولي رقم(1)"عرض القوائم المالية"، يجب أن يؤديان إلى الإفصاح الذي يأخذ في الاعتبار تأثير القضايا الناشئة والمهمة ومنها جائحة فيروس (COVID-19).

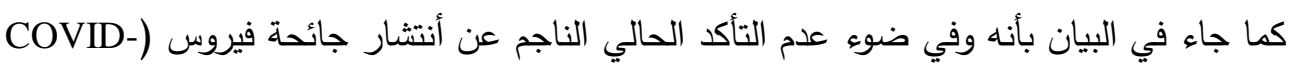
19)، فإن المنظمة ما زالت ملتزمة تمامًا بتطوير وتطبيق معايير محاسبية عالية، لما لها من أهمية في الأداء

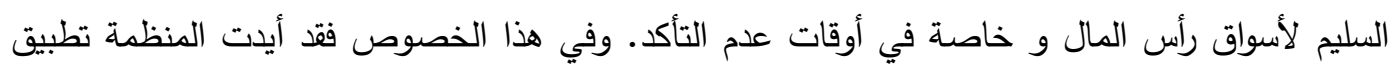
' للمزيد من التفاصيل حول تحليل خطة عمل IASB المحدثة يمكن زيارة الموقع الإكتروني (https://www.iasplus.com/en/news/2020/03/iasb-work-plan) 
المحاسبة عن الخسائر الائتمانية المتوقعة (ECL) وفقاً للمعيار رقم (9) " الأدوات المالية" خلال فترة عدم

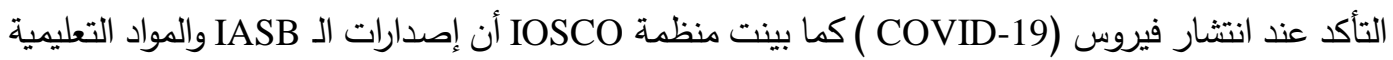

ذات الصلة لا تحتاج إلى تغيير أو حذف أو تعديل أو إضافة إلى متطلبات المعيار رقم (9) (9). كما أنه نتيجة جائحة فيروس(COVID-19)، يجب الفيل على مجلس معايير المحاسبة الدولية باعتباره

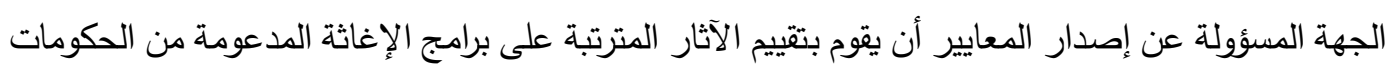

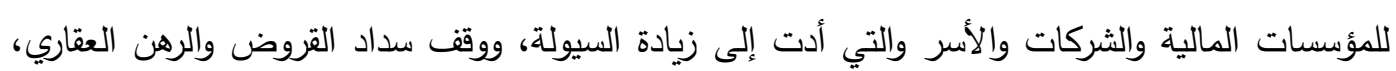

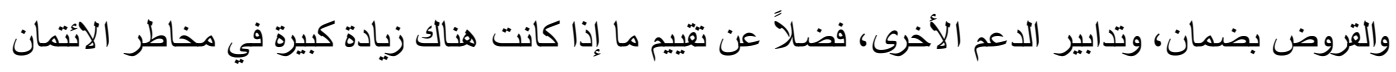

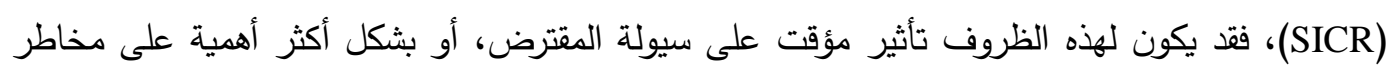

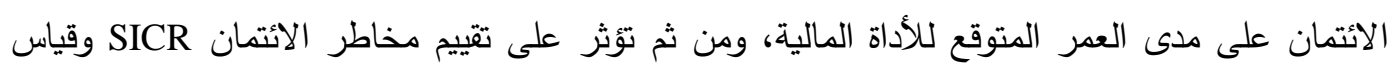

الخسائر الائتمانية المتوقعة.

r. موقف مجلس معايير المحاسبة الدولية لوحدات القطاع العام( IPSASB) في ضوء تطورات أنتشار جائحة فيروس (COVID-19)

COVID-19: RELEVANT IPSASB " في نيسان عام •r •r بياناً بعنوان) ACCOUNTING GUIDANCE موظفي مجلس (IPSASB) لتقديم نظرة حول قضايا إعداد التقارير المالية المرتبطة باستجابات الحكومة

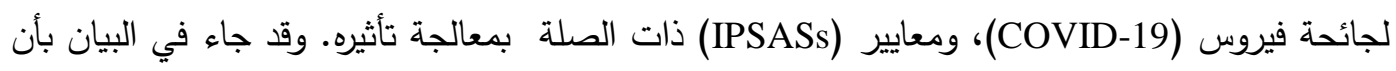

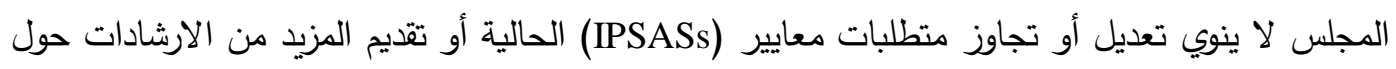

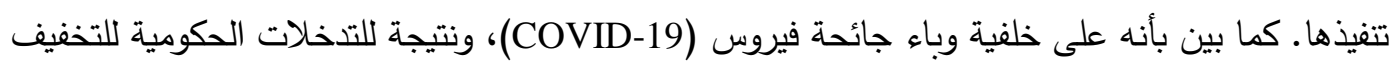

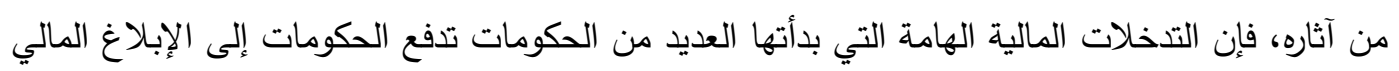

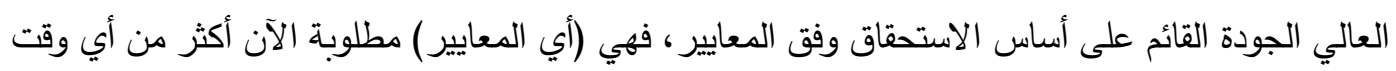
مضىى، إذ إن أساس الاستحقاق يوفر معلومات أفضل لصنع القرار ، ويحسن الثفافية حول كيفية استخدام الموارد العامة، ويسمح للمواطنين بمحاسبة صانعي القرار ووضع الحكومات في موضع أفضل للتصدي لتأثير الوباء على الموازنة العامة. لذلك فمن المهم الحفاظ على الجهود نحو اعتماد وتنفيذ أكبر لإعداد التقارير المالية على أساس الاستحقاق المحاسبي في القطاع العام. كما سلط البيان الضوء على على عدد من المعايير التي قد تكون قابلة للتطبيق من أجل تحديد العواقب الاقتصادية لمختلف أنواع المعاملات في ظل جائحة

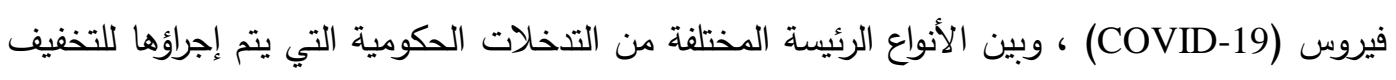
من آثار (COVID-19) والمتمثلة بالآتي: 1. الإنفاق الحكومي المباشر والمتمثل بتوفير الرعاية لأولئك الذين تضرروا بنسبة أكبر من الوباء، والحد

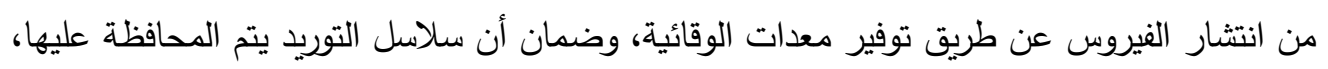

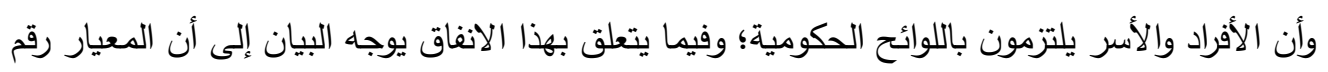


(9 (1) " المخصصات، والالتزامات المحتملة، والأصول المحتملة"، يوفر المتطلبات للتقييم المطلوبة، متى ما وجب الاعتراف بمخصص للتذخل الاقتصادي المخطط للحد من التأثير المالي لفايروس والاصول

.COVID-19

r. دعم الأفراد، والمتمثل بالزيادة في الحصول على الاستحقاقات الاجتماعية، كدعم الدخل، واستحقاقات

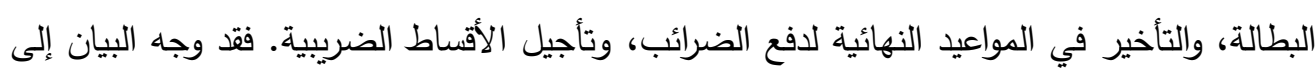

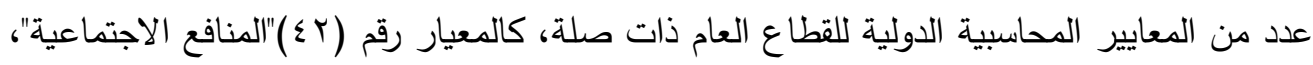
والمعيار رقم (9 ())" المخصصات، والالتزامات المحتملة، والأصول المحتملة" وخاصة ما يتعلق

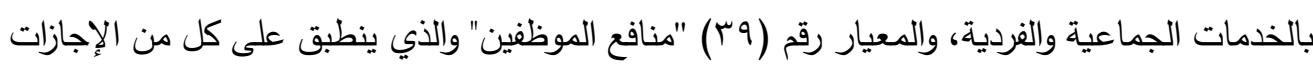
المرضية الإضافية ومدفوعات الاستغناء المقدمة لموظفي هيئات القطاع العام.

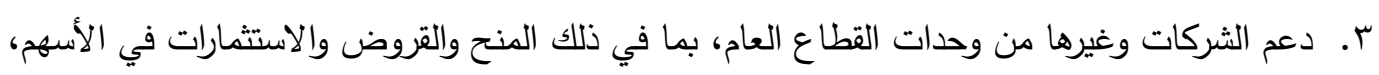

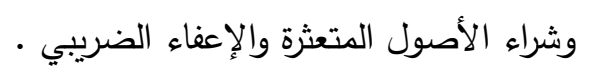
ـ. . دعم النظم المالية، بما في ذلك أدوات السياسة النقدية، على سبيل المثال تخفيض أسعار الفائدة، وشراء

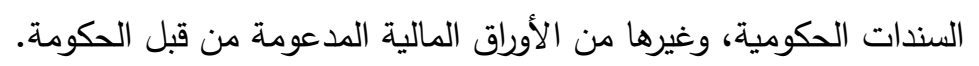

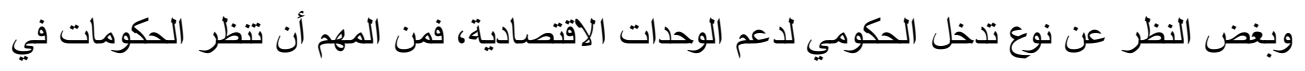
تأثير جائحة فيروس (COVID-19) على قائمة المركز المالي والأداء المالي. كما أنه من المهم لصانعي القرار الحصول على معلومات مالية محدثة من أجل فهم القدرات المتاحة للتدخلات المستقبلية أثناء الوباء

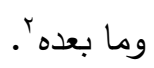

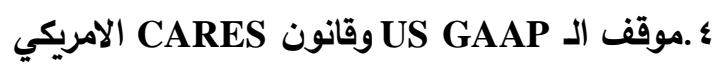

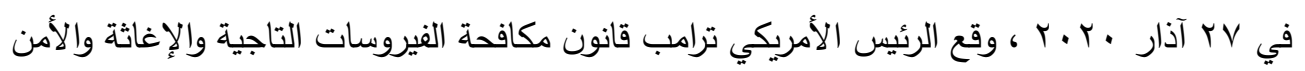

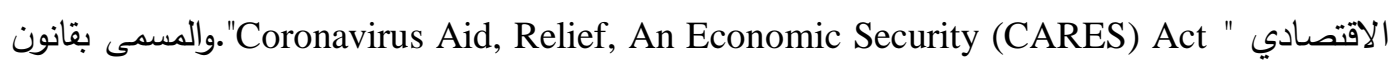
CARES الأمريكية SEC أو مجلس معايير المحاسبة المالية FASB بالتخفيف من بعض متطلبات المحاسبة وإعداد التقارير المالية بموجب GAAP الأمريكية. فقد أعطى قانون CARES إعفاء مؤقت اختياري من تطبيق معيار المحاسبة المالية رقم (1) " خسائر الائتمان الحالية المتوقعة" لبعض الوحدات مثل: مؤسسات الإيداع المؤمن

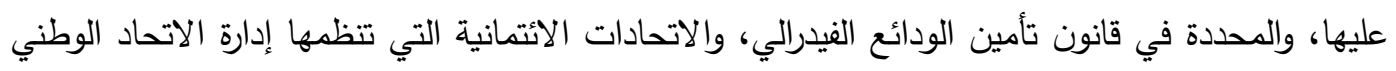

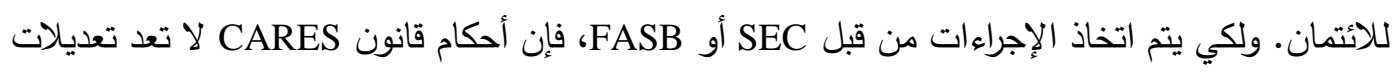
على GAAP الأمريكية.

r للمزيد من التفاصيل يمكن الرجوع إلى التقرير الصادر عن مجلس معايير المحاسبة الدولية لوحدات القطاع العام

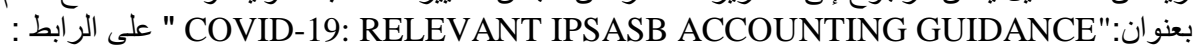
https://www.ipsasb.org/publications/covid-19-relevant-ipsasb-accounting-guidance 
ه موقف الهيئة الأوربية للأورلق المالية والاسواق The European Securities and Markets Authority

(ESMA)

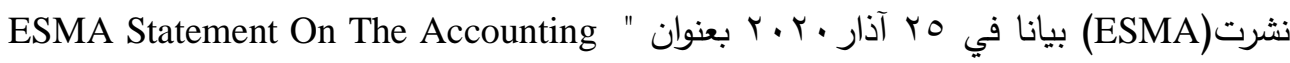
Implications Of The COVID-19 Economic Support And Relief Measures" الهاف منه جاء من أجل تعزيز التطبيق المتسق للمعايير الدولية للإبلاغ المالي (IFRS) في الاتحاد الأوروبي

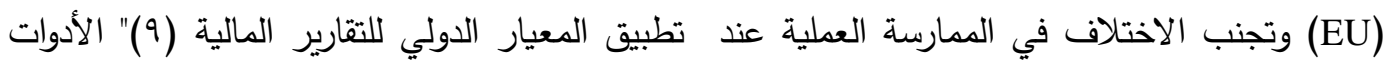
المالية" في ظل تشفي جائحة فيروس (COVID-19). كما تتاول البيان بثكل خاص الآثار المحاسبية والتدابير التي اتخذتها أو اقترحتها الحكومات الوطنية وهيئات الاتحاد الأوروبي لمعالجة التأثير الاقتصادي التئي لجائحة فيروس (COVID-19).

ومن وجهة نظر هيئة ESMA ، فان المعيار الدولي للتقارير المالية رقم (9) فيه مرونة كافية يمكن أن تعكس بدقة الظروف المحددة لتفشي جائحة فيروس (COVID-19) وتدابير السياسة العامة المرتبطة بها. ومن ثم فإنه يجب على معدي القوائم المالية ومدققي الحسابات مراعاة هذا البيان العام. كما بيّن البيان بأن هيئة ESMA قد نسقت مع الهيئة المصرفية الأوروبية (EBA) التي أصدرت بياناً حول الإطار الاحترازي

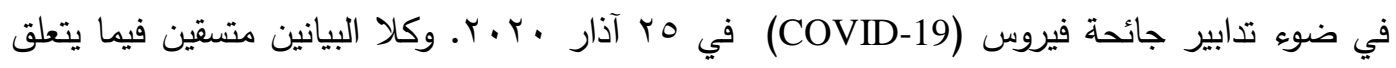
بالتقارير المالية.

4. Australian موقف مجلس معايير المحاسبة الاسترالي ومجلس معايير التدقيق والتأكيد الاسترالية Accounting Standards Board \& Auditing And Assurance Standard Board (AASB-AUASB)

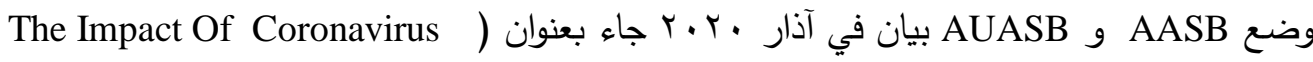
) وقد تضمن هذا البيان مجموعة من On Financial Reporting And The Auditor's Considerations الاسئلة الثائعة، الغرض منها، تقديم إرشادات حول بعض القضايا التي يجب على معدي التقارير المالية

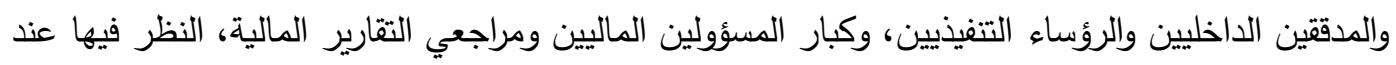
فحص تأثير جائحة فيروس (COVID-19) على التقارير المالية المرحلية والسنوية، وقد أوصى البيان الجهات

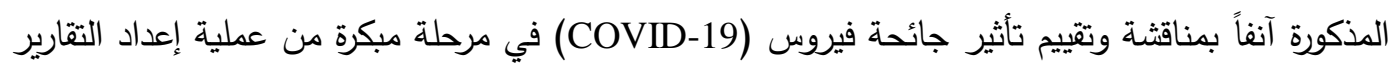

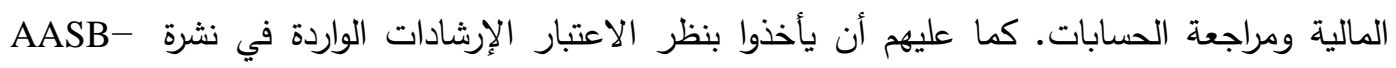

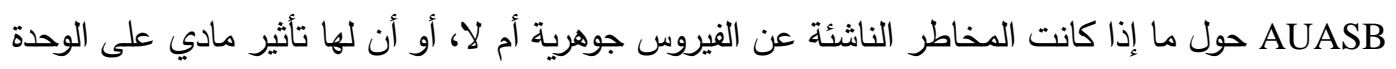

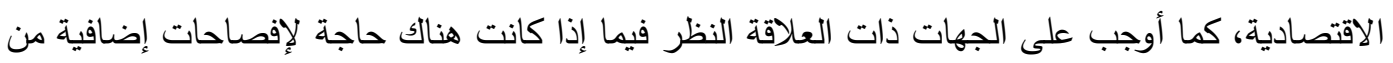
أجل توفير المزيد من المعلومات حول التوقعات المستقبلية للوحدة الاقتصادية. 
Voard of Monitoring And Auditing Profession مجلس مهنة مراقبة وتدقيق الحسابات العراقي V .

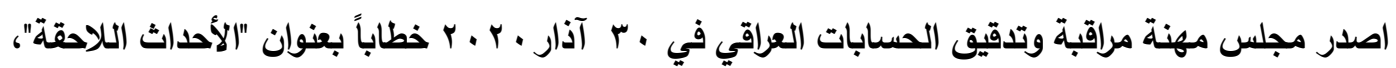

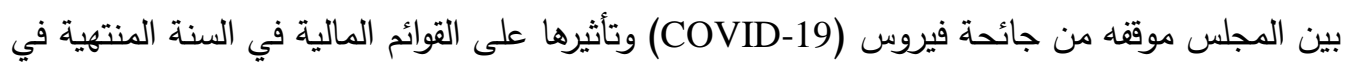

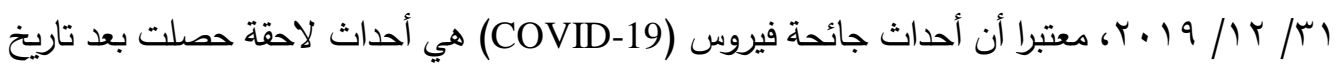

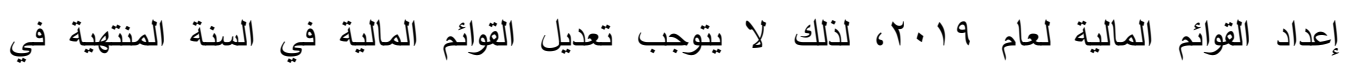

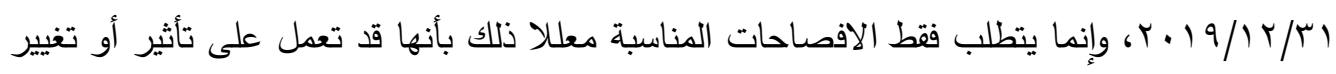

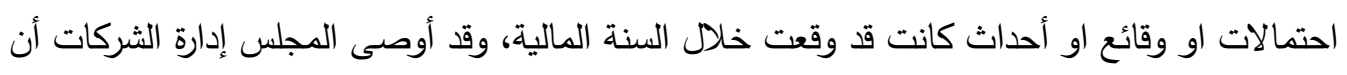

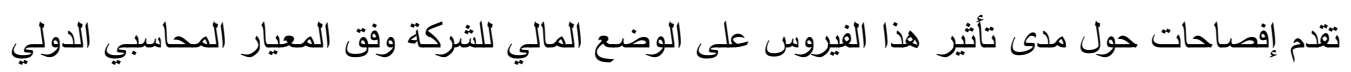

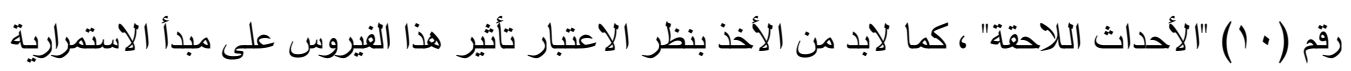

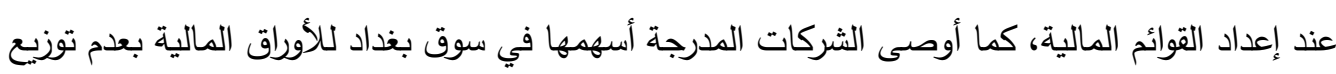

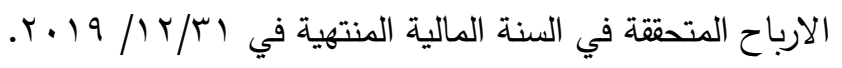

ومما سبق يتبين بأنه هناك شبه اتفاق بين الهيئات والمنظمات الدولية المحاسبية على عدم الحاجة

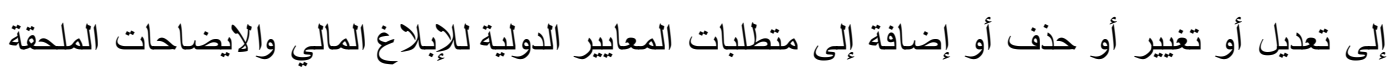

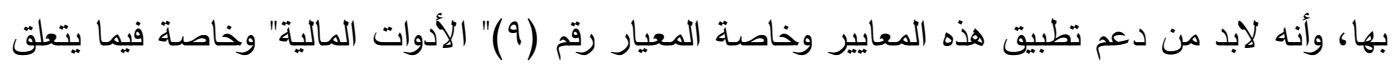
بمعالجة الخسائر الائتمانية المتوقعة، مستثنيا قانون CARES الامريكي بعض لطان الوحدات من تطبيق خسائر

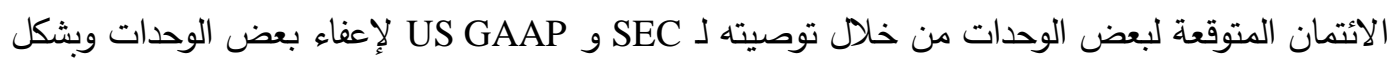

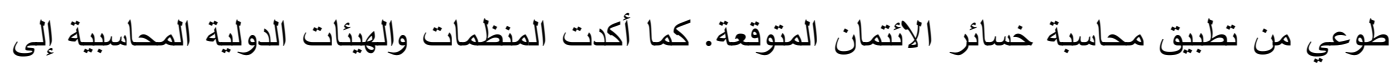
الحاجة إلى افصاحات إضافية في التقارير المالية لتعكس تأثيرات جائحة فيروس (COVID-19) على البيانات المالية، ويمكن الاستعانة بمعيار المحاسبة الدولي رقم(1 ) "عرض القوائم المالية" للقيام بهذا الأمر .

المحور الثالث: التحديات التي تواجه المحاسبين حول معالجة تأثير جائحة فيروس (COVID-19) على القوائم المالية

في ظل تطورات الأحداث التي يشهدها العالم في ظل تفشي جائحة فيروس (COVID-19)، لابد من الوقوف على هذه الأحداث، وتسليط الضوء على تأثيرها على القوائم المالية وعناصرها، في نهاية السنة المالية

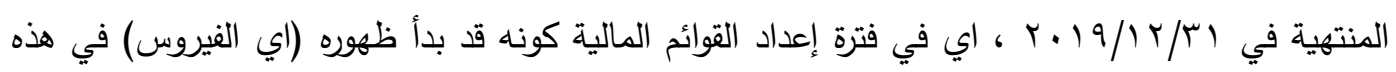

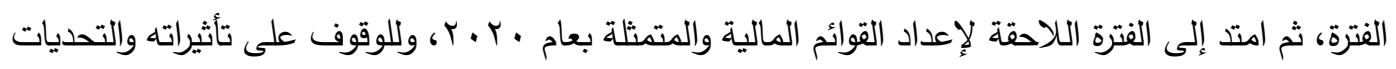
التي تواجه المحاسبين ومنظمي المهنة في معالجة هذه التأثيرات، تم تقسيم هذا المحور إلى الآتي: 
أولا: التحديات التي تواجه المحاسبين حول معالجة تأثير جائحة فيروس (COVID-19) على القوائم

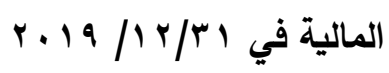

لتسليط الضوء على تأثير جائحة فيروس (COVID-19) على القوائم المالية وعناصرها، السنة المالية

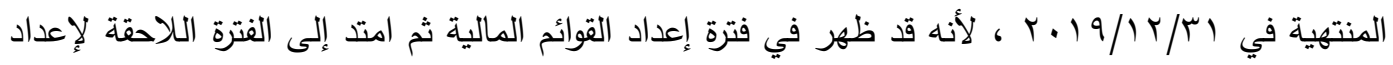

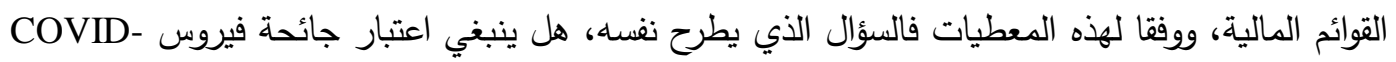

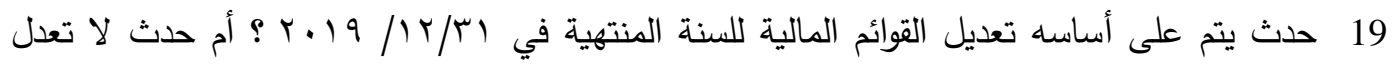
بموجبه القوائم المالية؟ بعبارة أخرى هل سيعرض تطبيق معيار المحاسبة الدولي رقم ( • ()"الأحداث اللاحقة بعد تاريخ الميزانية العمومية" القوائم المالية والوضع المالي للوحدات الاقتصادية بصورة عادلة في ظل جائحة

$$
\text { فيروس (COVID-19) بعديخ }
$$

فاذا عدنا إلى مفهوم الأحداث اللاحقة وفق معيار المحاسبة الدولي رقم(· ( ) " الأحداث بعد تاريخ

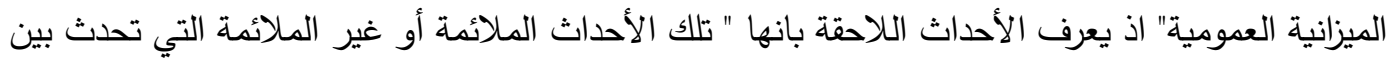
تاريخ الميزانية العمومية والتاريخ الذي تُعتمد فيه القوائم المالية للإصدار ـ وقد قسم المعيار الأحداث اللاحقة

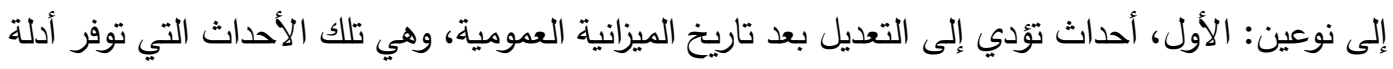

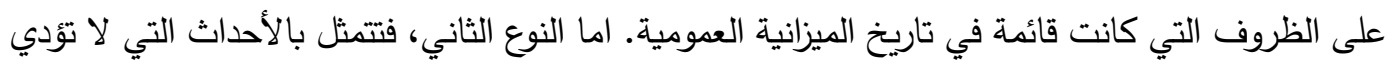

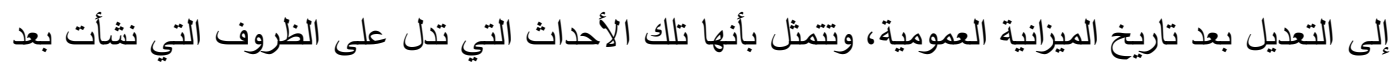

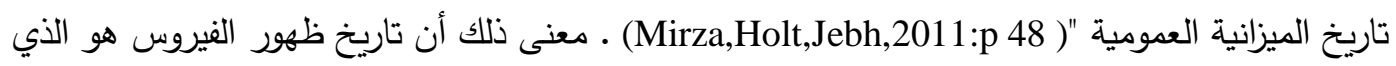

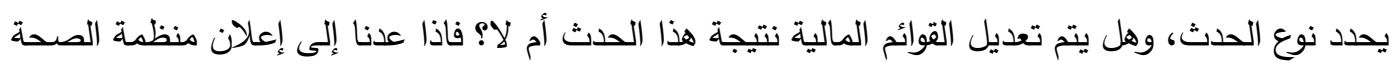

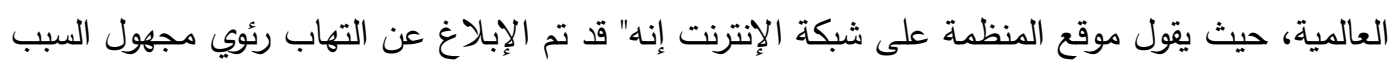

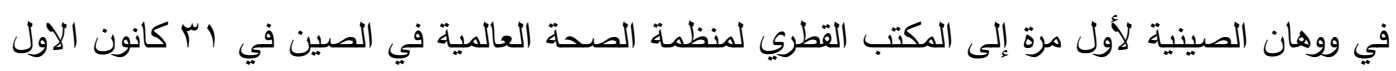

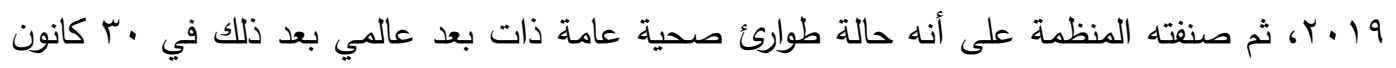

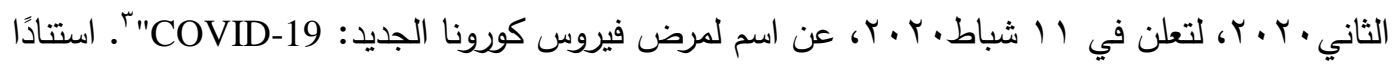
إلى توقيت هذه الأحداث، فإن تأثيرات فيروس (COVID-19) يعد حدثًا لاحقًا لا يُتوقع أن يؤثر على الئ المبالغ

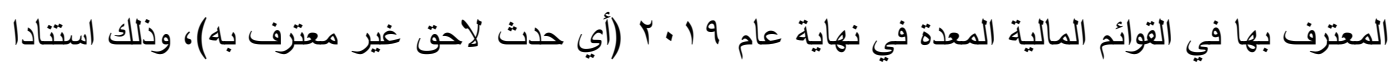
إلى مفهوم الأحداث اللاحقة وفق معيار المحاسبة الدولي رقم( • (1) " الأحداث بعد تاريخ الميزانية العمومية". وعليه فمن المرجح اعتبار تأثيرات الفيروس (COVID-19) حدثًا لاحقًا غير معترف به في الاجئ القوائم المالية

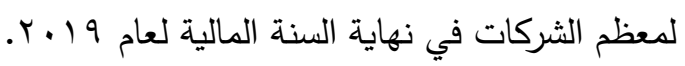
ولقد أيد هذا الرأي مجلس مهنة مراقبة وتدقيق الحسابات العراقي وكما ذكر آنفًا، كما أيد هذا الرأي(BDO,2020:1) إذ بيّن أن التوقعات والافتراضات ذات الصلة المستخدمة في إعداد البيانات المالية

https://arabic.euronews.com/2020/03/11/who- للمزيد من التفاصيل يمكن الرجوع إلى الموقع الالكثروني: declares-covid-19-pandemic-what-is-pandemic-exactl 
اعتبارا من اس كانون الاول 19 ـ r ستعكس إما تغييرًا طفيفًا أو معدومًا على القوائم المالية نتيجة لتفشي الفيروس(COVID-19). (2) (19)

يؤيد هذا التوجه ايضا شركة PWC ) حيث ذكرت في بيانها أنه لا

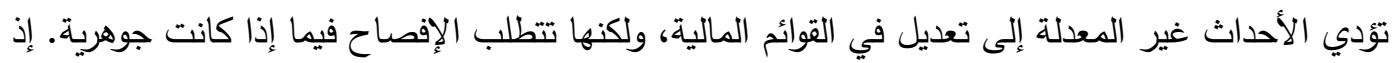

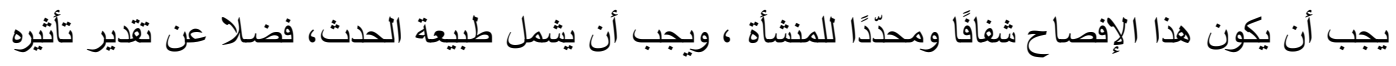
المالي، كما يجب أن تفكر الجهات في الكثف عن تأثير التطورات بعد تاريخ التقرير على القيمة الدفترية

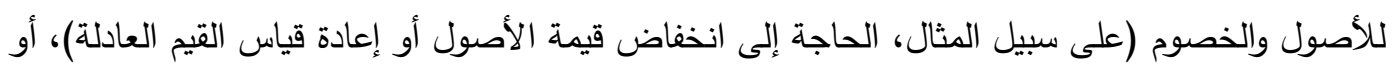
التأثير على الإيرادات أو على العهدة المقترضة (PWC,2020:2).

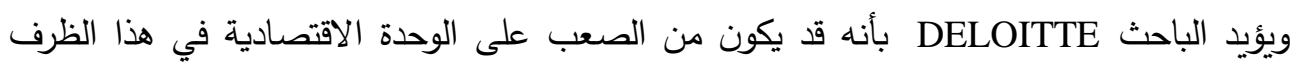

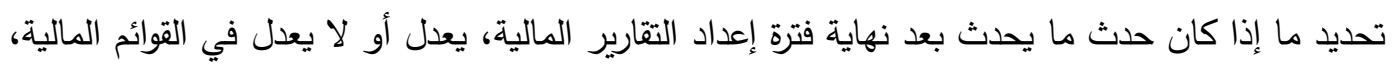

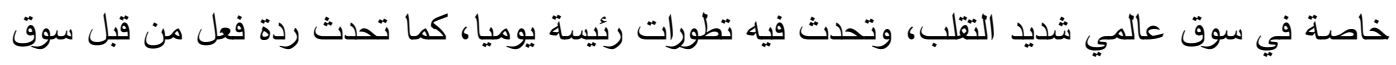

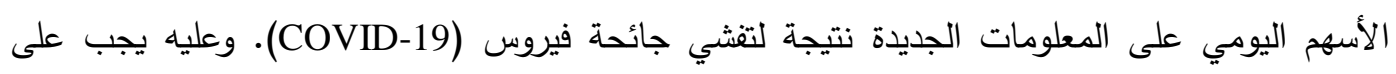
الوحدات النظر بعناية في ظروفها الفريدة ومدى تعرضها للمخاطر عند تحليل كيفية تأثير الأحداث الأخيرة، أحداث (COVID-19) على بياناتها المالية. وعلى وجه التحديد، ستحتاج الوحدات الاقتصادية إلى عمليات

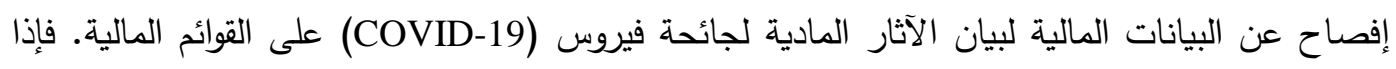

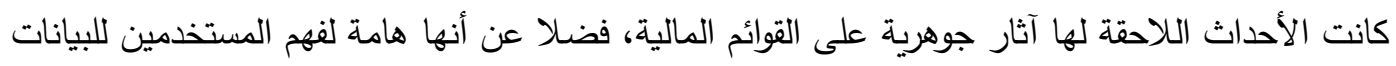

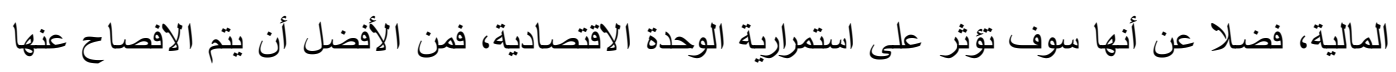

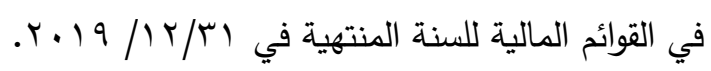
كما يرى الباحث بأن نتيجة للقيود التي تفرضها الحكومة على الوحدات الاقتصادية، والذي نتج عنها

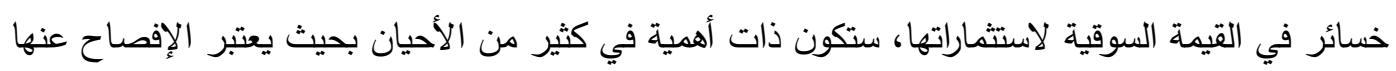

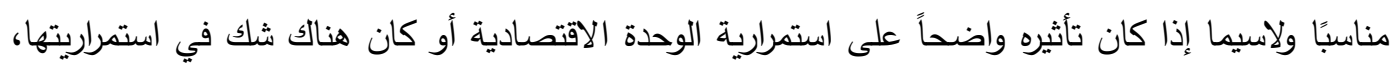

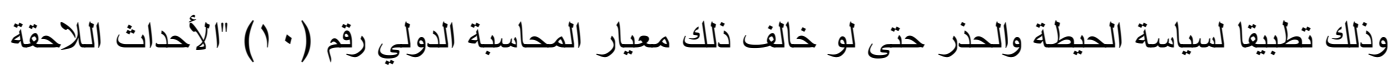
لتاريخ الميزانية" والذي بين بأنه عند إجراء تقييم لاستمرارية الوحدة، فان على الوحدة الاقتصادية النظر في الأحداث حتى تاريخ المصادقة على البيانات المالية.

ولغرض توضيح الكيفية التي يتم فيها القيام بالإفصاح عن تأثير جائحة فيروس (COVID-19) فقد التدات

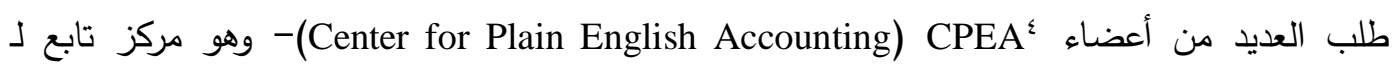
-(AICPA)

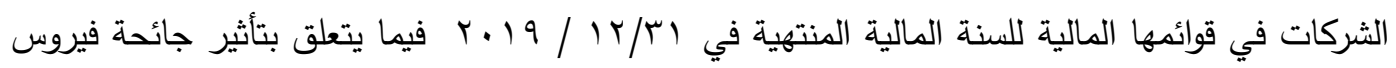

4 Center for Plain English Accounting, AICPA's National A\&A Resource Center. https://www.aicpa.org/ 
(COVID-19) فيروس (COVID-19) حدث لاحق من النوع الثاني (غير معترف به). وذلك منعاً للتضليل في القوائم

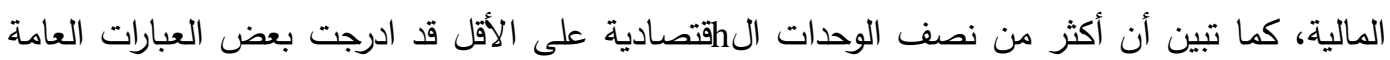
المتعلقة بـ (COVID-19) ككثف عن حدث لاحق من النوع الثانيْ . Austin,2020:1) ثانيا: التحديات التي تواجه المحاسبين حول معالجة تأثير جائحة فيروس (COVID-19) على القوائم

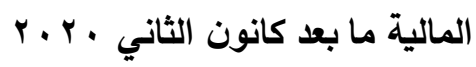

نتيجة لاستخدام التقديرات في العديد من البيانات المحاسبية، والتي يمكن أن تتأثر بجائحة فيروس (COVID-19) جائحة فيروس (COVID-19) على الوحدات الاقتصادية، ومن ثم على النتائج عملياتها ومركزها المالي لئي والإفصاحات المطلوبة في قوائمها المالية على سبيل المثال لا الحصر ، انخفاض قيمة الأصول المالية وغير المالية، وخسائر الائتمان المتوقعة، وقدرة الوحدة على الاستمرار، وقياسات القيمة العادلة، والتعديل في

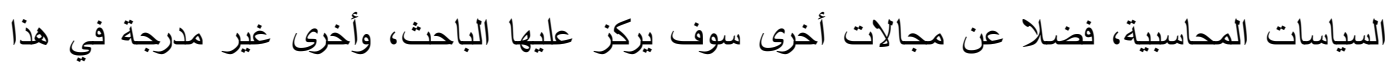

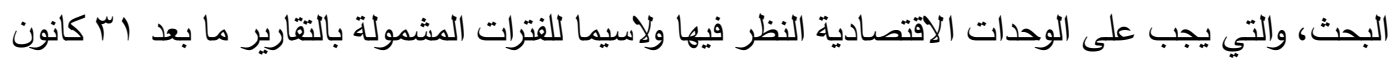

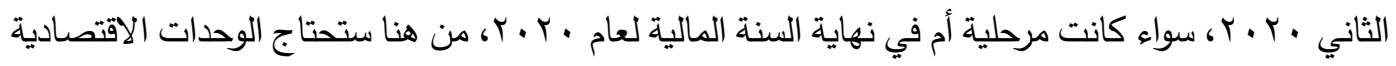
إلى بذل قصارى جهذها لإجراء تقديرات معقولة، وإعداد أدلة تدعم أساس هذه التقديرات، وتقديم افصاحات

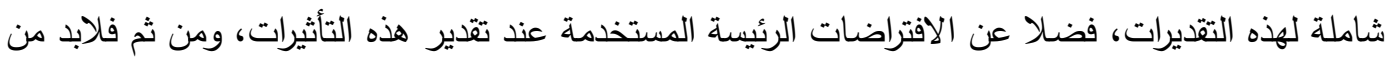
دمج تأثيرات جائحة فيروس (COVID-19) عند إعداد القوائم المالية.

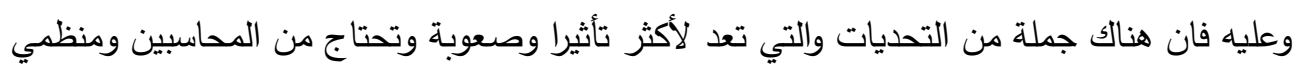

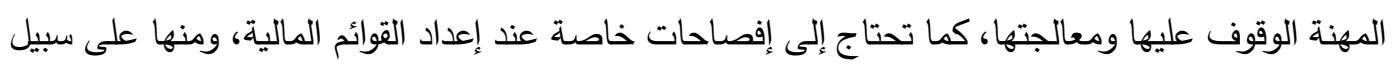

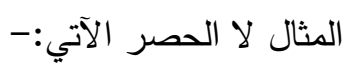

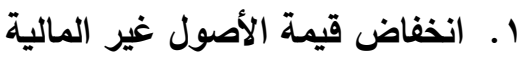

ينص معيار الدحاسبة الدولي (؟ب) على أن "الانخفاض في قيمة الأصول" إلى التأكد من عدم تسجيل

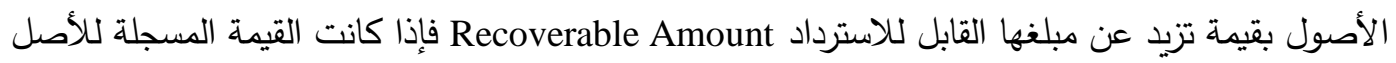
تزيد عن القيمة القابلة للاسترداد، فلابد من الاعتراف بخسارة تدني قيمة الأصول وتكوين مجمع لخسارة انخفاض القيمة للأصول التي سبق وتم الاعتراف بتدني قيمتها. إن نطاق الأصول الخاضعة لمتطلبات

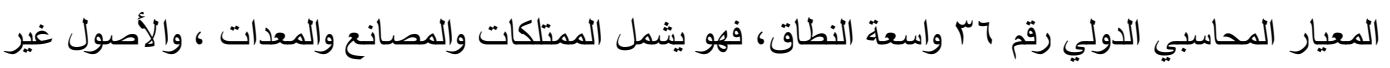

• للمزيد من الامثلة حول كيفية الافصاح عن تأثيرات COVID-19 باعتباره كحدث من النوع الثاني يمكن الرجوع إلى: Austin,M.,2020, Consequences of COVID-19,Illustrative Public Company Disclosures,31March, Center for Plain English Accounting,AICPA's National A\&A Resource Center. 
الملموسة بما فيها الثهرة، والاستثمارات العقارية، والثركات التابعة والثركات الزميلة والمشاريع المشتركة

.(Hamidat,2014:228)

إن العوامل الناتجة عن جائحة فيروس COVID - 19 تشير إلى أن القيمة الدفترية لوحدة توليد الطاقة

قد لا يمكن استردادها، ومن هذه العوامل الآتي(Deloitte,2020:5) أ. انخفاض الطلب على منتجات أو خدمات الوحدة الاقتصادية. ب. زيادة التكاليف / انقطاع الأعمال بسبب قضايا سلسلة التوريد. ج. إلغاء أو تأجيل الطلبات من قبل العملاء. د. الحاجة إلى تقديم تنازلات كبيرة للعملاء.

هـ هناك عملاء على قدر كبير من الأهمية يواجهون صعوبات مالية أو صعوبات في التدفق النقدي ، ومن ثم قد تضطر الوحدة الاقتصادية إلى تصفية بعض أصولها بسرعة.

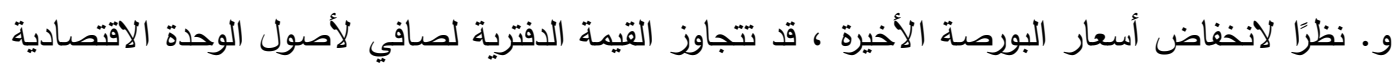

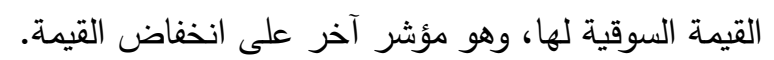

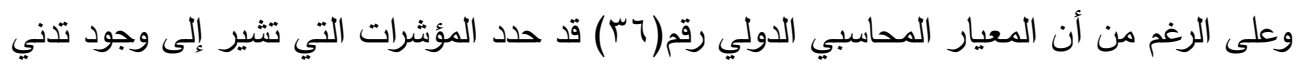

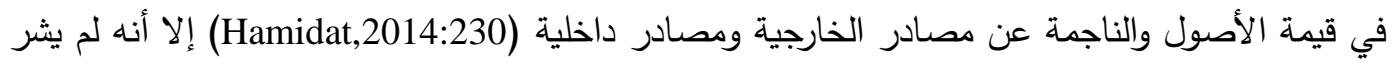
إلى الظروف التي تمر بها الوحدات الاقتصادية في ظل تفشي جائحة

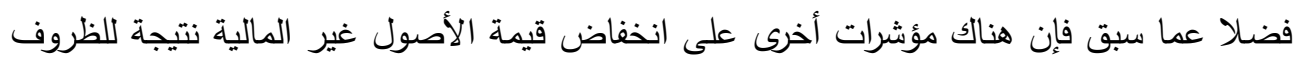

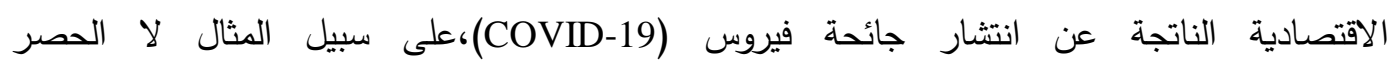
الآتي:(GTIL,2020:2)

أ. تغييرات كبيرة في الطريقة التي يتم بها استخدام الأصل أو من المتوقع استخدامه (على سبيل المثال ،

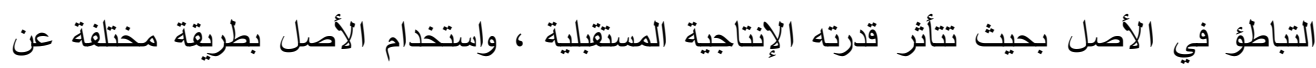
الغرض الذي امتلك من أجله - (مثل ذلك استخدام الأصل في دعم مكافحة فيروس (COVID-19) - والتي قد تقلل من قدرتها الإنتاجية المستقبلية). ب. تغييرات كبيرة في العوامل القانونية أو مناخ الأعمال التي يمكن أن تؤثر على على قيمة الأصل (على سبيل المثال تتوقع المنثأة انخفاضًا في صادراتها إلى الاسواق الخارجية نتيجة لإغلاق الحدود لفترة طويلة ). ج. انخفاض في أسعار الفائدة السوقية، مما قد يتسبب في انخفاض قيمة الأصول قيد الاستخدام. د. انخفاض أو توقف الحاجة إلى الخدمات التي يقدمها الأصل. هـ الثك حول قدرة الوحدة على الاستمرار كوحدة مستمرة هو مؤشر عام لانخفاض القيمة لجميع الأصول.

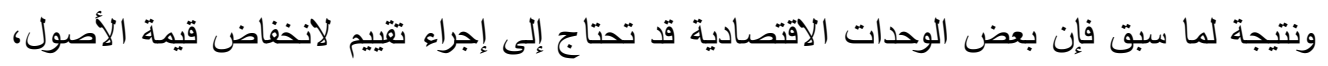

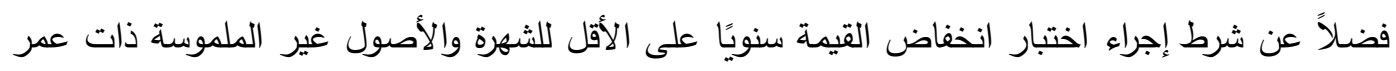
إنتاجي غير محدد. وقد تواجه الإدارة تحديات كبيرة في إعداد الميزانيات والتنبؤات اللازمة لتقدير المبلغ القابل عيل 
للاسترداد للأصل. وقد تحدد الإدارة أن استخدام منهج التدفق النقدي المتوقع هو أكثر الوسائل فعالية لعكس أوجه عدم التأكد لجائحة فيروس (COVID-19) عند تقديرها للمبلغ القابلة للاسترداد. وربما يكون المثال الأكثر تحديًا و المرتبط بمعلومات التتبؤ هو اختبار انخفاض قيمة الأصول غير المالية (على سبيل المثال،

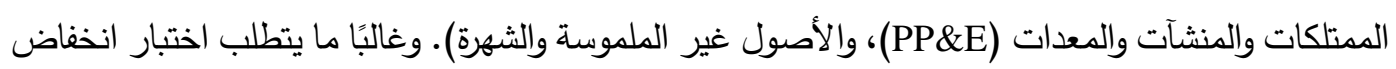

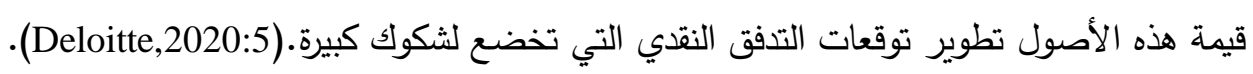

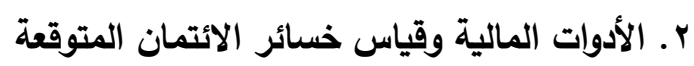

بموجب المعيار الدولي للتقارير المالية (9) "الأدوات المالية" ، يجب الاعتوان المتراف بخسائر الائتمان المتوقعة (ECLs)

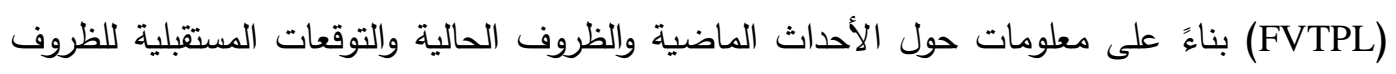
الاقتصادية.

يجب مراعاة التوقعات الاقتصادية السلبية وصعوبات التدفق النقدي التي يعاني منها العملاء نتيجة لجائحة فيروس (COVID-19) في تتبؤات الوحدة الاقتصادية للظروف المستتبلية، والتي قد تؤدي إلى زيادة في مخصصات الخسائر الائمانية المتوقعة ECL لتعكس الآتي (GTIL,2020:2):أ. هناك احتمال كبير في تخلف بعض المقرضين عن السداد، ويشمل ذلك حتى أولئك الذين لا يظهرون حاليًا

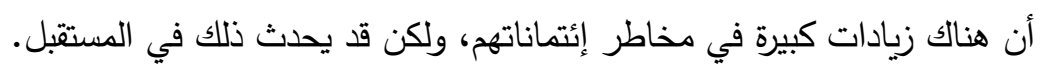

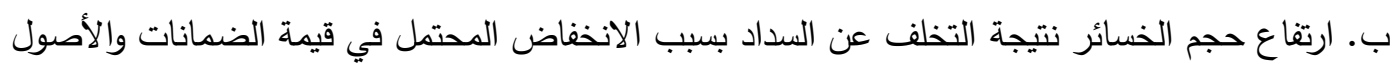

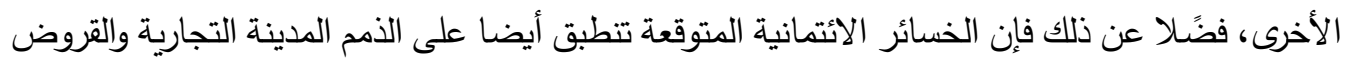

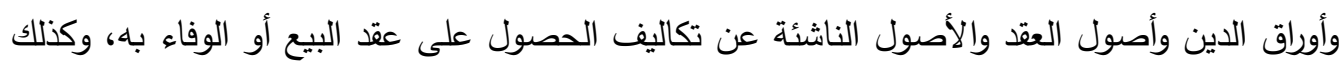

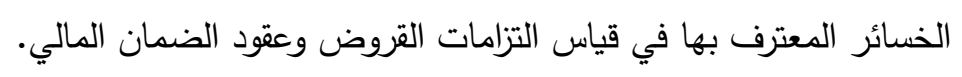
برض الاستمرارية

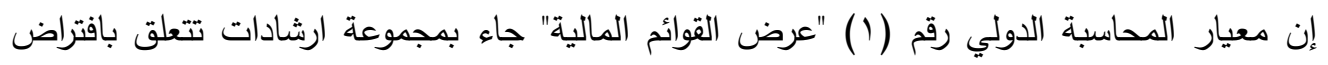

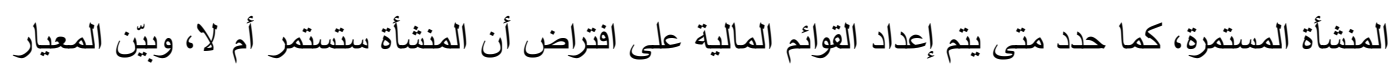

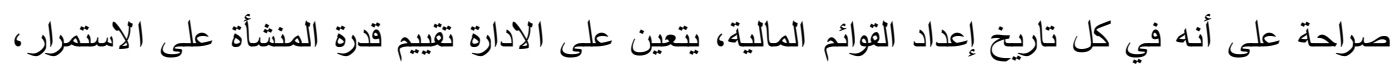
والنظر في كل ما هو متاح من معلومات تتعلق بالمستقبل، وهي على الاقل اثنا عشر شهرًا من تاريخ القوائم

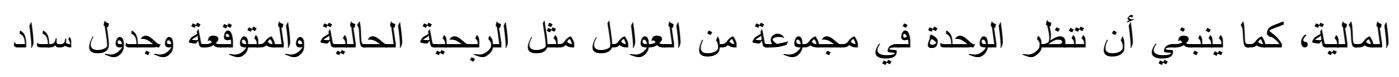

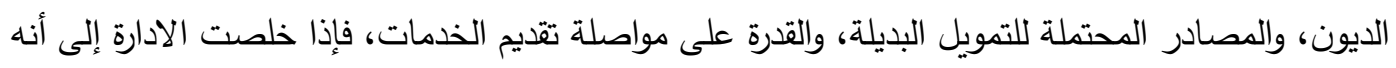

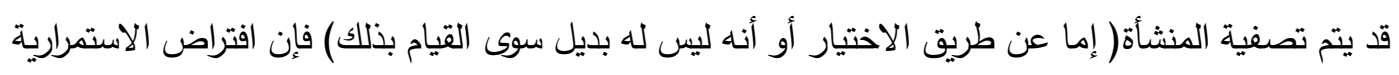
لن يكون مناسبا، وقد يتعين إعداد القوائم المالية على أساس آخر مثل التصفية.(GTIL,2020: 11)

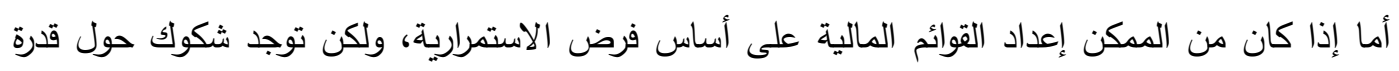

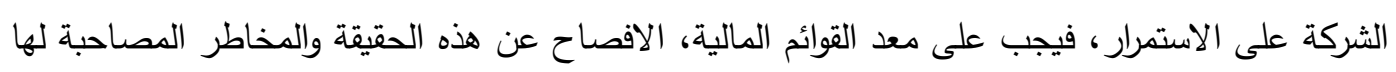


أرديني

في ملحق خاص بالقوائم المالية أو في هامش الميزانية العمومية، فضلا عن أنه يجب الإبلاغ عن المخاطر التي تتعرض لها الثركة في تقرير الادارة (IDW,2020:11).

ونتيجة لانتشاء جائحة فيروس (COVID-19) والآثار المرتبطة به، تحتاج الوحدات الاقتصادية إلى إعادة النظر فيما إذا كانت لديها، في ظروفها الخاصة، القدرة على الاستمرار كمنشأة مستمرة على الأقل، يتضمن تقييم قدرة الوحدة على الاستمرار كمنشأة مستمرة إصدار حكم، في وقت معين، حول النتائج المستقبلية غير المؤكدة للأحداث أو الظروف. وسيتطلب هذا من الوحدة أن تتظر ، من بين أمور أخرى منها على سبيل المثال الآتي: (Dellitte,2020:6):أ. أ. مدى الاضطراب التشغيلي ب. تتاقص الطلب المحتمل على المنتجات أو الخدمات. ج. الالتزامات التعاقدية المستحقة أو المتوقعة خلال سنة واحدة. د. السيولة المحتملة ونقص رأس المال العامل.

هـ الوصول إلى مصادر رأس المال الحالية (على سبيل المثال، خط الائتمان المتاح، والمعونة الحكومية). ع ـقياس القيمة العادلة

مع تقلبات السوق في الوقت الحالي والناتجة من تأثيرات جائحة (COVID-19)، يجب على الوحدات

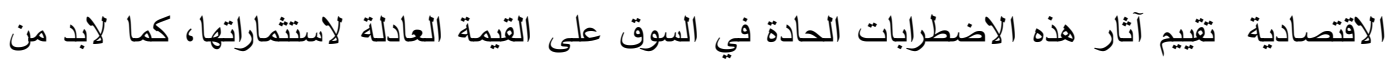
إعادة النظر في ما إذا كانت هذه الاستثمارات منخفضة القيمة. فقد تتأثر الاستثمارات في سندات الدئ لادين سلبًا بتوسيع هوامش الأتمان، وقد لا يتمكن مصدرو سندات الدين من سداد المبالغ المستحقة بذمتهم، وقد تتأثر

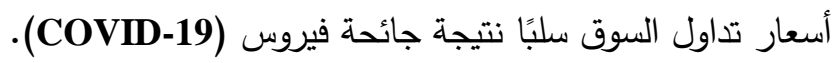
وقد تشهد الاستثمارات في الأوراق المالية في الأسهم انخفاضًا كبيرًا في القيمة العادلة، وقد تواجه الاستثمارات في حقوق الملكية تحديات تثير إلى أن الاستثمار قد لا يكون قابلًا للاسترداد. (BDO,2020:11)

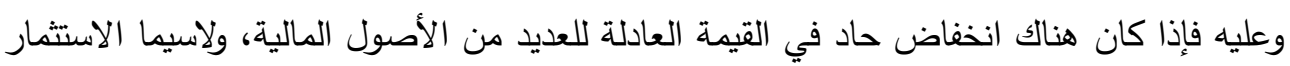

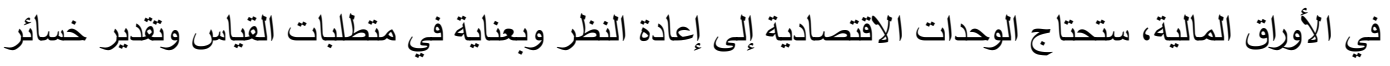
انخفاض القيمة العادلة وتطبيقها. ه م.السياسات المحاسبية نتيجة لمبدا الاتساق في العرض (Consistency of presentation)، يتوجب على الوحدة الاقتصادية

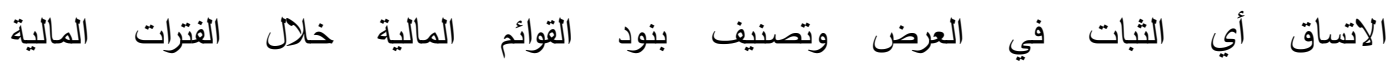
المتتالية(Hamidat,2014:31) ومن ثم يجب الاحتفاظ بطرق الاعتراف والقياس المطبقة على البيانات المالية

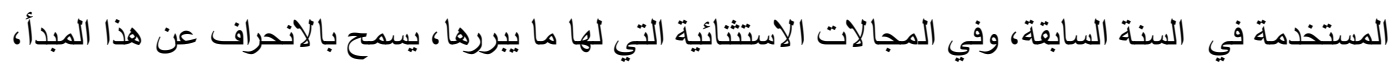
وذلك لضمان قدرة الوحدة الاقتصادية التي تعد القوائم المالية على التكيف مع الظروف المتغيرة باستخدام طرائق محاسبية مختلفة، وقد أعطي هذا السماح بالعدول عن هذا المبدأ في حال ما إذا كانت القوائم المالية 
تعطي نظرة أفضل عن حالة الأصول المالية وغير المالية والارباح، وبما أن جائحة فيروس (COVID-19) حدث خارجي وخطير وله تأثير مماثل على جميع الوحدات وبيئاتها، فإن تعديل سياسة محاسبية ما في

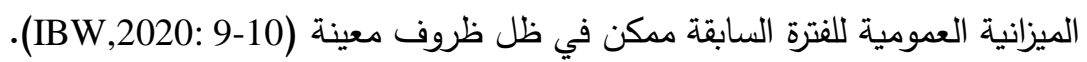
فقد تؤدي آثار تفشي جائحة فيروس COVID-19 إلى انخفاض حجم المبيعات أو اضطرابات كبيرة

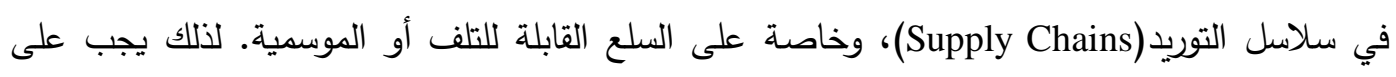

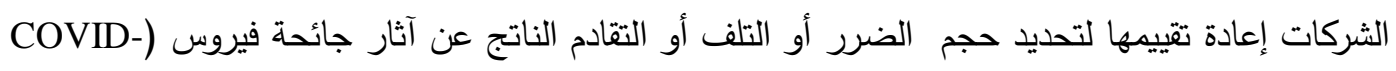

كما لابد من قياس المخزون باستخدام أي طريقة أخرى غير طريقة LIFO أو طريقة جرد التجزئة "

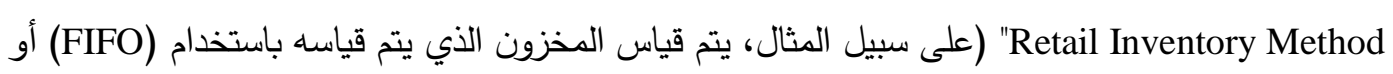

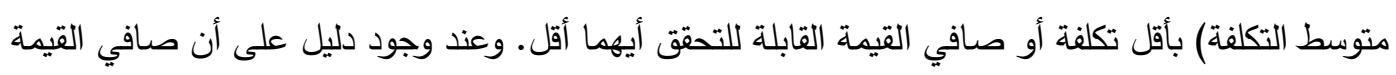
القابلة للتحقق للمخزون أقل من تكلفته، يعترف بالفرق كخسارة في أرباح الفترة التي حدث فئه وديها. كما يجب تعديل المخزون الذي تم قياسه باستخدام طريقة LIFO أو طريقة جرد التجزئة إلى التكلفة

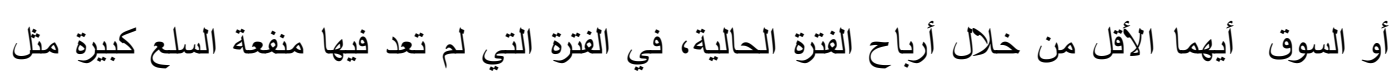
تكلفتها. فضلا عن ذلك، في حالة انخفاض الإنتاج، يجب على الكيانات مراعاة أن النفقات العامة الثابتة يتم

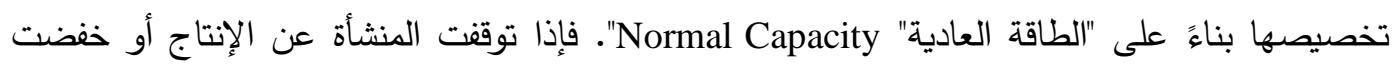
الإنتاج بشكل كبير لفترة من الوقت، فإن أجزاء كبيرة من النفقات العامة الثابتة المخصصة على الإدلى الانتاج (مثل

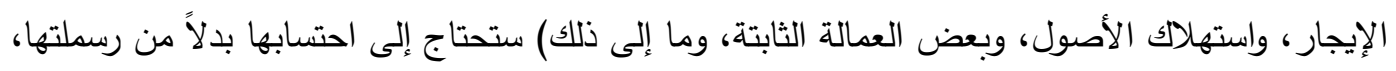

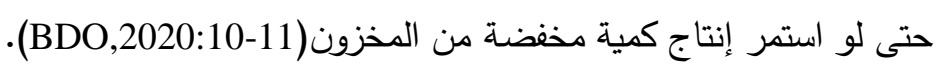

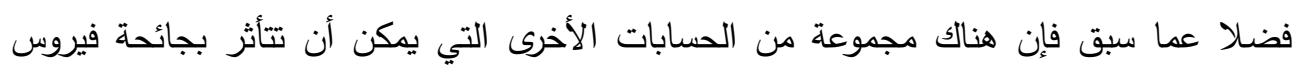
(COVID-19)

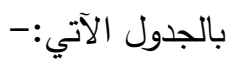




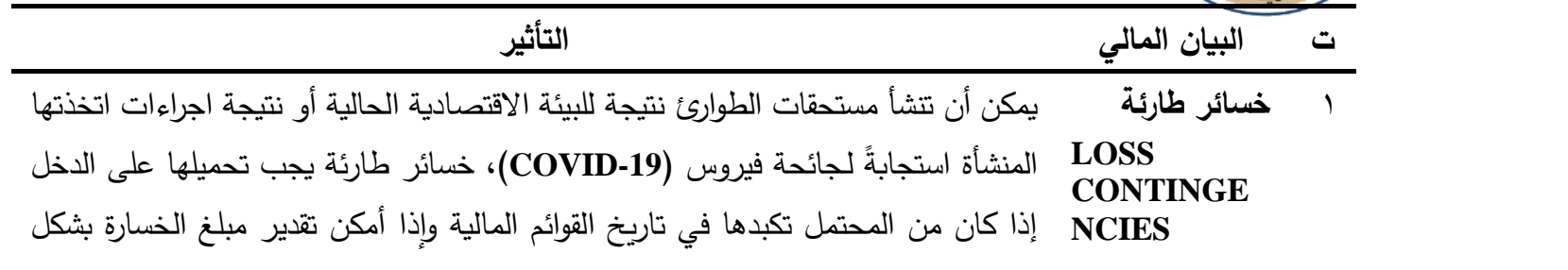

يحق للوحدة الذي لم تكن تحصل فيما سبق على مساعدة حكومية، الحصول على مساعدة حكومية نتيجة جائحة فيروس (COVID-19). قد تحتاج الإدارة إلى وضع سياسة محاسبية فيما يتعلق بالمساعدة الحكومية التي يجب أن تكون مناسبة ومتوافقة مع متطلبات معيار

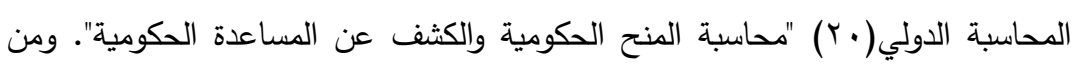
الضروري التمييز بين المساعدة الحكومية والمنح الحكومية والتأكد من عدم الاعتراف بالمنح إلا عند استيفاء معايير الاعتراف التي جاء بها معيار المحاسبة الدولي رقم(· ب). قد تتضمن بعض المساعدات الحكومية تأجيل مدفوعات الضرائب أو الإعفاءات الضريبية الأخرى. كما أن المعالجة المحاسبية قد يلزم احتساب مخصصات الضرائب بموجب معيار المحاسبة

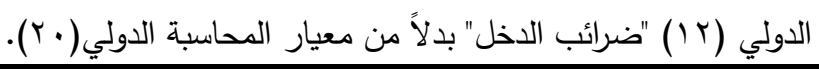

قد يكون للمنشأة بوليصة تأمين تغطي الخسائر الناجمة عن توقف الأعمال. فإذا اضطرت المنشأة إلى التوقف مؤقتًا عن الأعمال نتيجة لجائحة كورونا (COVID-19)، فقد يحق لها استرداد بعض أو كل خسائرها من شركة التأمين الخاص بها. قد تكون مثل هذه المطالبات

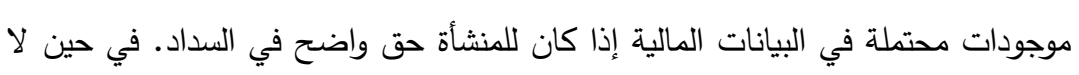
يتم الاعتراف بالأرباح / الأصول المحتملة في البيانات المالية للمنشأة ما لم تكن مؤكدة فعليًا (وفقًا للمعيار المحاسبة الدولي لr " لالمخصصات والمطلوبات المحتملة والأصول المحتملة")،وعليه سيتم الإفصاح عنها في الملاحظات على البيانات المالية عندما يكون وجودها محتملًا ويمكن الاعتراف بها كايراد في البيانات المالية فقط عندما تكون مؤكدة فعليًا ، على سبيل المثال عند قبول المطالبة من قبل شركة التأمين. وعند النظر في مطالبات التأمين ، يجب تقييم قدرة شركات التأمين على تسوية المطالبة في الوقت المناسب

نتيجة للبيئة الاقتصادية الصعبة التي تمر بها الوحدة الاقتصادية نتيجة جائحة كورونا (COVID-19)، قد تفكر المنشأة أو تنفذ خطط لإعادة الهيكلة، على سبيل المثال : بيع أو

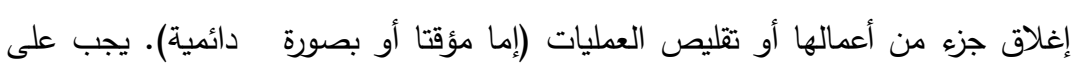

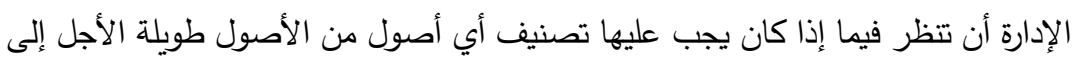
T المساعدة الحكومية

Government Assistance

r لانقطاع الأعمال Insurance Claims for Business Interruption أصل محتفظ به للبيع أو إذا كان أي جزء من أعمالها مؤهلاً للعرض كعملية متوقفة. يتعين

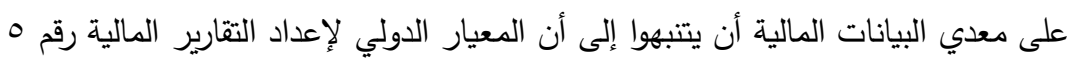
"الأصول غير المتداولة المحتفظ بها للبيع والعمليات المتوقفة" لديه شروط محددة ليتم

غ غ الهيكلة

Restructuring Plans

الاحتفاظ بها للبيع. 
سوف تؤدي التغييرات في النشاط الاقتصادي التي يسبها جائحة كورونا (COVID-19)

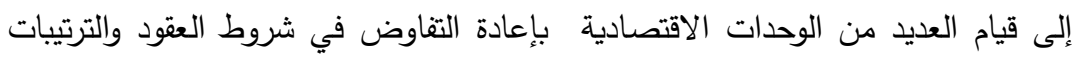

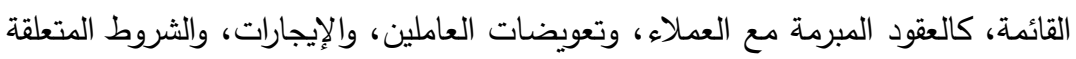

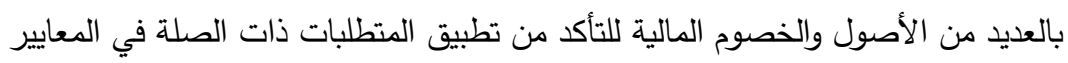

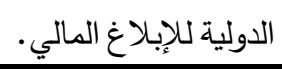

قد تتوقع الوحدات الإقتصادية خسائر بسبب انخفاض الطلب على منتجاتها أو تعطل سلسلة 7

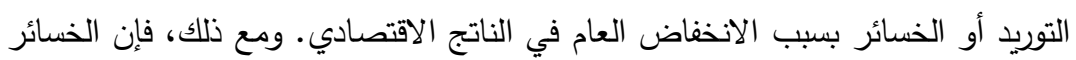

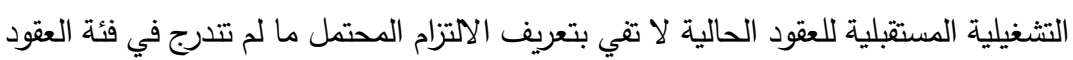

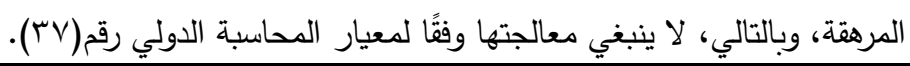

يمكن أن تؤثر جائحة كرورنا (COVID-19) على الثهرة من خلال الآتي:

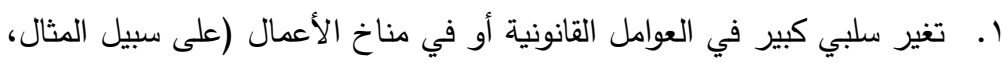

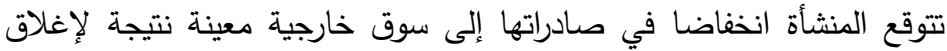

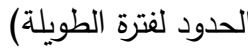

r. ت. فقدان الموظفين الرئيسين بثكل دائم (على سبيل المثال، الوفاة)

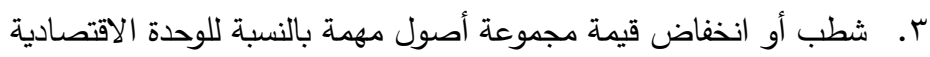

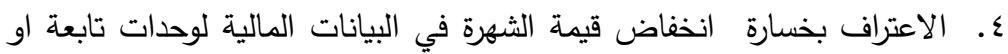

$$
\text { وحدات مستثمر بها . }
$$

•. انخفاض كبير في سعر سهم الوحدة الاقتصادية، مما قد يؤدي إلى تجاوز القيمة

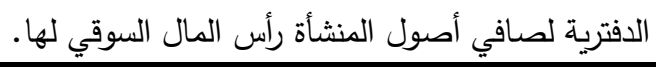

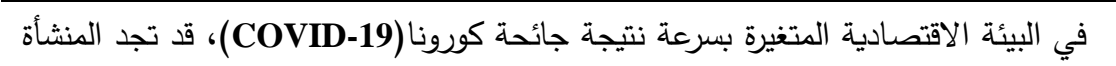

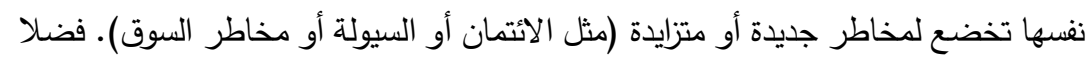

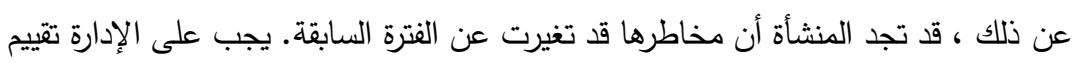

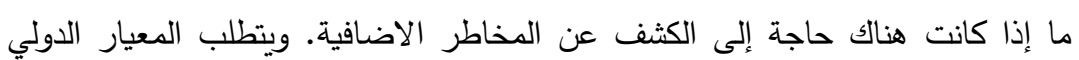
للتقارير المالية أن تفصح المنشأة عن تحليل الحساسية (بما في ذلك الإلف الإفصاحات الكمية)

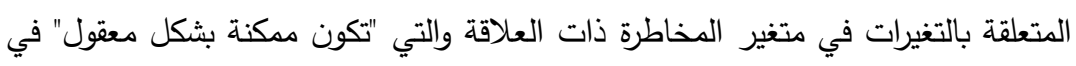
^ الإفصاح مخاطر الأدوات المالية

Financial Instrument

Risk Disclosures تاريخ التقرير •. وهنا قد تحتاج الإدارة إلى إجراء حسابات الحساسية باستخدام نطاق أكبر

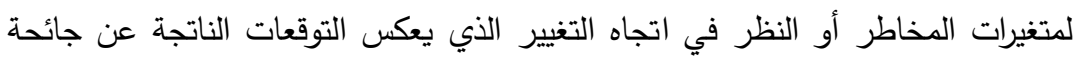


ومما سبق يتبين أن هناك جملة من التحديات التي تواجه المحاسبين ومنظمي المهنة لمعالجة تأثير جائحة كورونا (COVID-19) على الوحدات الاقتصادية ، وعلى نتائج عملياتها والمركز المالي والإفصاحات المطلوبة في قوائمها المالية، فانخفاض قيمة الأصول غير المالية نتيجة للظروف الاقتصادية الناجمة عن انتشار جائحة كورونا (COVID-19)، قد تضع المحاسبين أمام تحديات كبيرة في إعداد التتبؤات اللازمة لتقدير مبالغ الأصول القابلة للاسترداد، والذي يتطلب اختبار انخفاض قيمة هذه الأصول التي تخضع للشكوك الكبيرة. أما خسائر الائتمان المتوقعة، فلابد ان تعكس صعوبات التدفق النقدي التي يعاني منها العملاء نتيجة جائحة كورونا (COVID-19) في تتبؤات الوحدة الاقتصادية للظروف المستقبلية، والتي قد تئدي إلى زيادة في مخصصات الخسائر الائتمانية المتوقعة ECL نتيجة لتخلف بعض المقرضين عن السداد، والخسائر

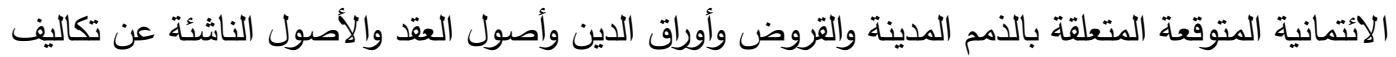

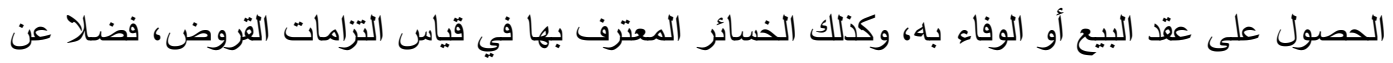
ارتفاع حجم الخسائر الناجمة عن التخلف عن السداد بسبب الانخفاض المحتمل في عقود الضمان المالي والأصول الأخرى. كما لابد من مراعات فرض الاستمرارية، خاصة إذا كان هناك شكوك حول استمرارية الوحدة الاقتصادية والذي يتطلب من المحاسبين، الافصاح عن هذه الحقيقة والمخاطر المصاحبة لها في هري ملحق خاص بالقوائم المالية أو في هامش الميزانية العمومية، فضلا عن أنه يجب الإبلاغ عن المخاطر التي لإني

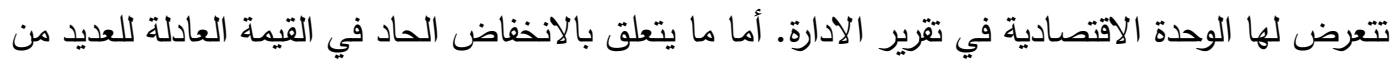

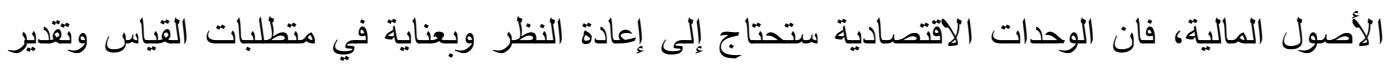

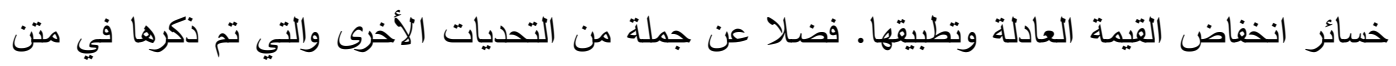
البحث والتي تحتاج من المحاسبين ومنظمي المهنة الوقوف عليها ومعالجتها عند إعداد القوائم المالية، والتي ظهرت نتيجة لعدم التأكد الناجمة عن الأحداث التي سبيتها جائحة كورونا (COVID-19) والتي ستحتاج إلى معالجات محاسبية وإفصاحات وعناية خاصة من قبل المحاسبين، كما تحتاج إلى بذل جهود كبيرة لإجراء تقديرات معقولة، وإعداد مستندات تدعم هذه التقديرات، فضلا عن الافتراضات الرئيسة المستخدمة عند تقدير

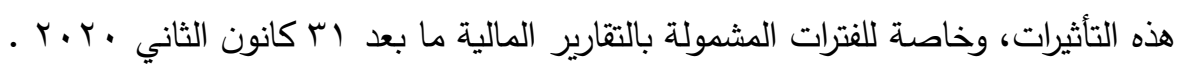

$$
\text { من خلال ما تم ذكره في متن البحث يتبين الآتي: }
$$

1. هناك إجماع من قبل الهيئات والمنظمات المهنية الدولية المحاسبية على تعزيز التطبيق المتسق للمعايير الدولية للإبلاغ المالي (IFRS) وعلى قدرة المعايير في معالجة تأثيرات جائحة كورونا (COVID-19)

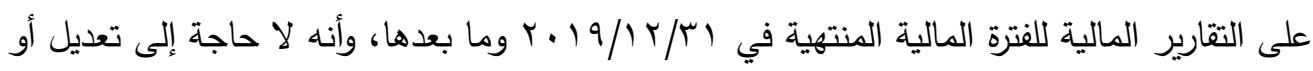
تغيير أو حذف أو إضافة إلى متطلبات المعايير الدوليةللإبلاغ المالي والايضاحات الملحقة بها والمعمول بها حاليا، ولاسيما معيار الإبلاغ المالي الدولي رقم (9)" الأدوات المالية" وذلك لأنه فيه مرونة كافية 
يمكن أن تعكس بدقة الظروف المحددة لتفثي جائحة كورونا (COVID-19) وتدابير السياسة العامة

$$
\text { المرتبطة بها. }
$$

r. محليا لم يصدر أي بيان من قبل أي جهة محاسبية كنقابة المحاسبين والمدققين العراقية وديوان الرقابة

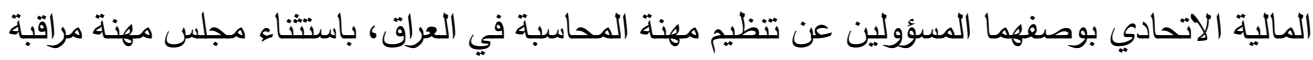

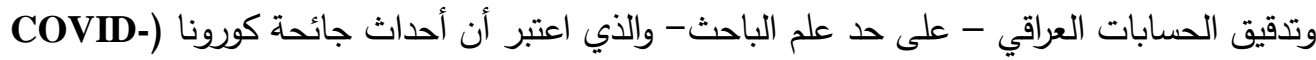

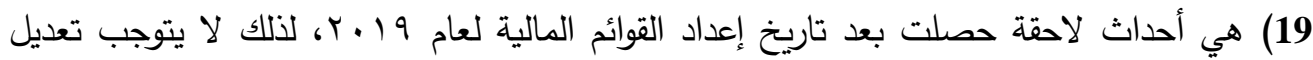

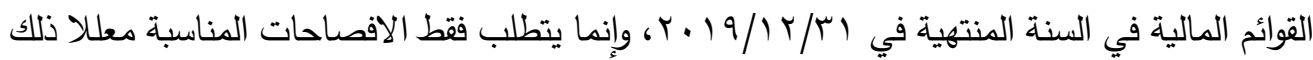

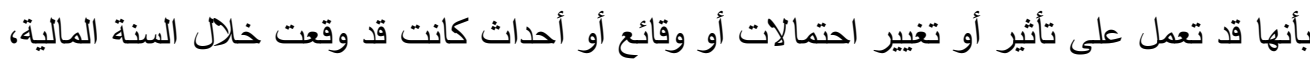

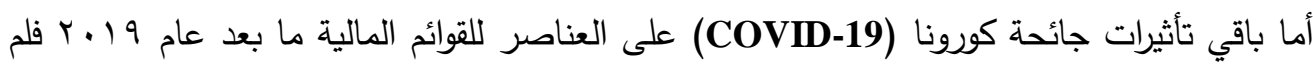
يصدر أي بيان بشأنها. ז. هناكَ تأثير لجائحة كورونا (COVID-19) على الوحدات الاقتصادية، ومن ثََّّ على البيانات المالية، ويمكن أن يؤدي استمراره من حيث المدة والحجم إلى تأثير سلبي طويل الأمد على النتائج المالية والقوائم

$$
\text { المالية للوحدات الاقتصادية. }
$$

ء. نتيجة التقلب الثديد في السوق العالمي و التطورات اليومية وردة الفعل من قبل سوق الأسهم اليومي

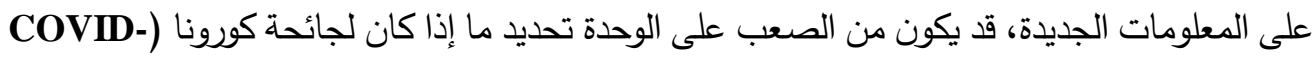
19) والذي انتشر بعد نهاية فترة إعداد التقارير المالية لعام 9 ـــ، يعدل أو لا يعدل في القوائم المالية.

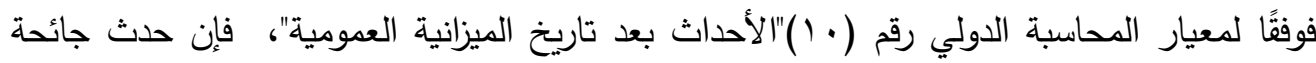
كورونا (COVID-19) يعد حدثًا لاحقًا لا يتم على أساسه تعديل القوائم المالية للسنة المنتهية في

$$
. r \cdot 19 / T / T^{\prime}
$$

ه. هناك جملة من التحديات والتي تعد الأكثر تأثيراً على البيانات المالية للفترة ما بعد كانون الثاني عام

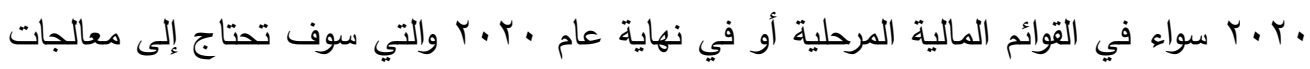
محاسبية وإفصاحات وعناية خاصة من قبل المحاسبين عند إعداد القوائم المالية والتي ظهرت نهاء نتيجة لحالة عدم التأكد في الأحداث الناجمة عن جائحة كورونا (COVID-19) منها:

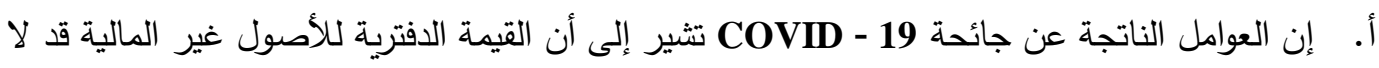
يمكن استردادها نتيجة لانخفاض قيمة الأصول غير المالية والتي تشمل الممتلكات والمصانع والمعدات، والأصول غير الملموسة بما فيها الثهرة، والاستثمارات العقارية، والثركات التابعة والثركات الزميلة والمشاريع المشتركة.

ب. من المحتمل أن تكون هناك صعوبات في التدفق النقدي للعملاء والخسائر الائمانية المتوقعة المتعلقة بالذمم المدينة والقروض، وكذلك الخسائر المعترف بها في قياس التزامات القروض نتيجة لجائحة كورونا 
والتي لابد أن تتعكس في تنبؤات الوحدة الاقتصادية والتي قد تؤدي إلى زيادة في (COVID-19)

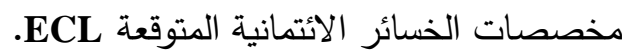

ت. فيما يتعلق بفرض استمرارية الوحدة الاقتصادية، إذا كانت هناك شكوك حول قدرة الوحدة على الاستمرار ، فلأل

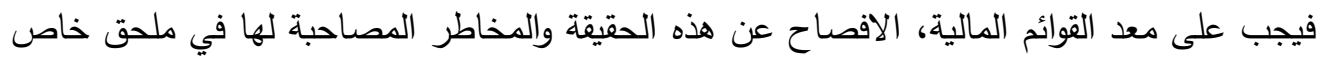

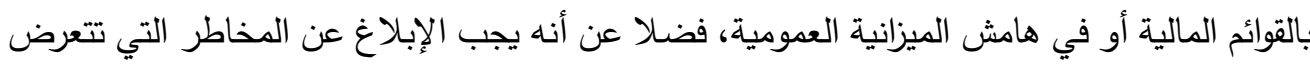

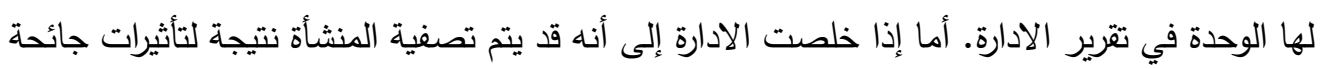
كورونا (COVID-19) فإن افتراض الاستمرارية لن يكون مناسبًا، وقد يتعين إعداد القوائم المالية على لئل

أساس التصفية.

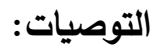

1. يجب على الوحدات الاقتصادية النظر بعناية في ظروفها الخاصة ومدى تعرضها للمخاطر عند تحليل كيفية تأثير جائحة كورونا (COVID-19) على بياناتها المالية. فإذا كانت الأحداث اللاحقة لها آثار

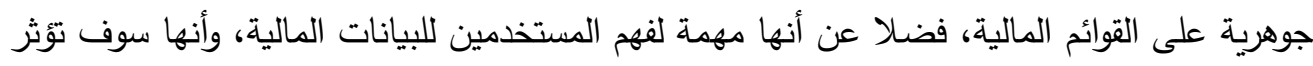
على استمرارية الوحدة الاقتصادية، فمن الافضل أن يتم الافصاح عنها في القوائم المالية للسنة المنتهية

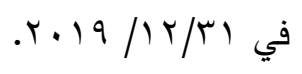

r. على الوحدات الاقتصادية إعادة النظر وبعناية في متطلبات القياس وتقدير خسائر انخفاض القيمة العادلة وتطبيقها فيما إذا كان هناك انخفاض حاد في القيمة العادلة في الأصول المالية، ولا سيما

$$
\text { الاستثمار في الأوراق المالية. }
$$

r. لابد للوحدات الاقتصادية أن تعكس صعوبات التدفق النقدي التي يعاني منها العملاء نتيجة لجائحة كورونا (COVID-19) في تتبؤات الوحدة الاقتصادية والتي قد تؤدي إلى زيادة في مخصصات الخسائر الائتمانية المتوقعة ECL نتيجة لتخلف بعض المقرضين عن السداد، والخسائر المتعلقة بالذمم المدينة والقروض وأوراق الدين وأصول العقد والأصول الناشئة عن تكاليف الحصول على عقد البيع أو لئي

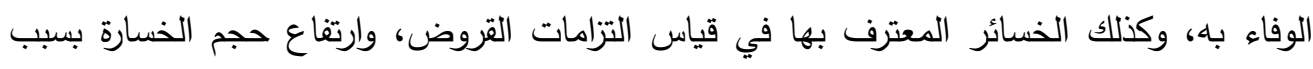
التخلف عن السداد نتيجة للانخفاض المحتمل في عقود الضمان المالي والأصول الأخرى.

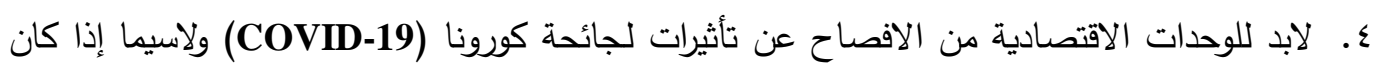

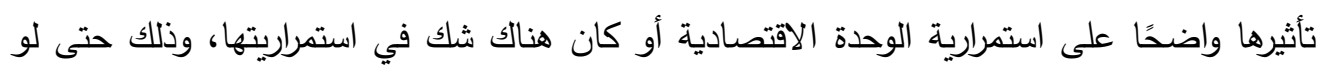

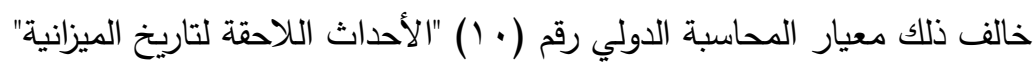

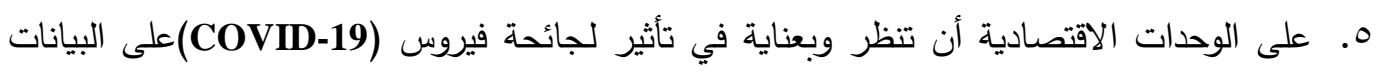

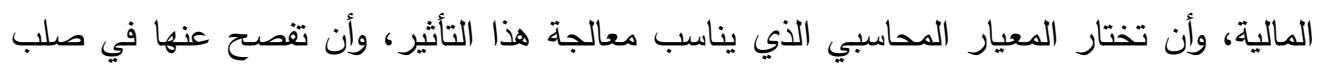

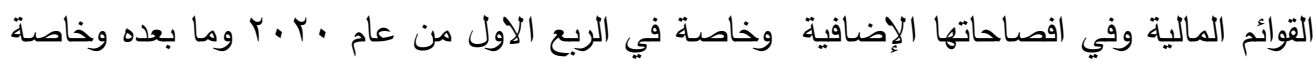
فيما يتعلق بالثكوك حول استمرارية الوحدة الاقتصادية. 
7. على الوحدات الاقتصادية إجراء تقييم لانخفاض قيمة الأصول، فضلًا عن شرط إجراء اختبار انخفاض

$$
\text { القيمة سنويًا على الأقل شهرة والأصول غير الملموسة ذات العمر الإنتاجي غير المحدد. }
$$

\section{Refrence}

AASB-AUASB,2020, The Impact of Coronavirus on Financial Reporting and the Auditor's Considerations. MARCH 2020, https://www.aasb.gov.au.

BDO,2020, COVID-19 - Accounting, Reporting and Other Related Considerations,

CARES Act,2020, Coronavirus Aid, Relief, and Economic Security CARES Act would provide optional temporary relief from CECL accounting, https://www.iasplus.com/en/news/2020/03/cares-act-cecl.

Deloitte.2020, IFRS in Focus,Accounting considerations related to the Coronavirus 2019 Disease, March 2020, www.iasplus.com, www.deloitte.com.

GTIL, Grant Thornton International Ltd,2020, COVID-19: Financial Reporting and Disclosures, 1/4/2020, https://www.grantthornton.global/en/insights/supportingyou-to-navigate-the-impact-of-covid-19/COVID-19-Financial-Reporting-andDisclosures/

Hamidat, Jumaa, 2014, International Financial Reporting Standards Expert Curriculum, (IFRS EXPERT), The International Arab Society of Certified Accountants, ISBN: 978-9957-8696-1-8, Amman, Jordan. www.iascaociety.org.

Illuzzi,K., Landes,Ch., Durak,R., and Groskopf,Th.,2020, Consequences of COVID-19 Potential Auditing hallenges, Center for Plain English Accounting aicpa.org/CPEA | cpea@aicpa.org, April 01, 2020.

IOSCO, 2020, IOSCO Statement on Application of Accounting Standards during the COVID-19 Outbreak, 03 April 2020, https://www.iasplus.com/en/news/2020/04/iosco-covid-19.

IPSASB, 2020, COVID-19: RELEVANT IPSASB ACCOUNTING GUIDANCE, Apr 06, 2020 :https://www.ipsasb.org/publications/covid-19-relevant-ipsasb-accountingguidance

PWC ,Price water house Coopers(2020), A look at current financial reporting issues; Accounting implications of coronavirus, 12 February 2020, www.pwc/structure for further details.

Austin,M.,2020, Consequences of COVID-19,Illustrative Public Company Disclosures,31March, Center for Plain English Accounting,AICPA's National A\&A Resource Center. aicpa.org/CPEA

Deloitte,2020, IFRS in Focus,Expected Credit Loss Accounting Considerations Related to Coronavirus 2019 Disease, March 2020, www.iasplus.com, www.deloitte.com.

ESMA (The European Securities and Markets Authority 2020,ESMA statement on the accounting implications of the COVID-19 economic support and relief measures, 25 March, https://www.esma.europa.eu/sites/default/files/library/.

IASB,2020, IASB updates work plan in view of COVID-19 developments, 27 Mar, https://www.iasplus.com/en/news/2020/03/iasb-work-plan

IFRS,2020, IASB publishes statement on IFRS 9 and COVID-19, 27 Mar 2020, https://www.iasplus.com/en/news/2020/03/iasb-ifrs-9-covid-19.

IFRS,2020, IFRS 9 and covid-19, 27 Mar 2020 https://www.iasplus.com/en/news/2020/03/iasb-ifrs-9-covid-19. 
أرديني

Mirza, Abbas Ali, Holt, Graham. Jebh, Uriel, Magnus, 2011, International Financial Reporting Standards, Book and Guide, Actual Implementation (Wiley), translated by the Arab Society of Certified Accountants, Jordan.

The Republic of Iraq, Board of Monitoring And Auditing Profession, Events after the

Reporting Period",No.105,30/3/2020." 